\title{
Coordinated Targeting of Galanin Receptors on Cholangiocytes and Hepatic Stellate Cells Ameliorates Liver Fibrosis in Multidrug Resistance Protein 2 Knockout Mice
}

Anca D. Petrescu, ${ }^{* \dagger}$ Stephanie Grant, ${ }^{* \dagger}$ Elaina Williams, ${ }^{\star \dagger}$ Gabriel Frampton, ${ }^{\dagger}$ Natalie Parks, ${ }^{\S}$ Hanna Blaney, ${ }^{\llbracket}$ Marcus Davies, Rebekah John, Evan H. Reinhart, Matthew McMillin, ${ }^{* \star}$ and Sharon DeMorrow ${ }^{* \dagger \ddagger}$

From the Research Division, Central Texas Veterans Health Care System, ${ }^{*}$ Temple; the Division of Pharmacology and Toxicology, ${ }^{\dagger}$ College of Pharmacy, and the Department of Internal Medicine, ${ }^{\ddagger}$ Dell Medical School, The University of Texas at Austin, Austin; the Texas Tech University, ${ }^{\S}$ Lubbock; and the Department of Internal Medicine, "Baylor Scott \& White Health, Temple, Texas

Accepted for publication October 22, 2019.

Address correspondence to Sharon DeMorrow, Ph.D., College of Pharmacy, Dell Medical School, The University of Texas at Austin, 1601 Trinity St., Bldg. B, Austin, TX 78701. E-mail: sharon. demorrow@austin.utexas.edu.

\begin{abstract}
Galanin (Gal) is a peptide with a role in neuroendocrine regulation of the liver. In this study, we assessed the role of Gal and its receptors, Gal receptor 1 (GalR1) and Gal receptor 2 (GalR2), in cholangiocyte proliferation and liver fibrosis in multidrug resistance protein 2 knockout (Mdr2KO) mice as a model of chronic hepatic cholestasis. The distribution of Gal, GalR1, and GalR2 in specific liver cell types was assessed by laser-capture microdissection and confocal microscopy. Galanin immunoreactivity was detected in cholangiocytes, hepatic stellate cells (HSCs), and hepatocytes. Cholangiocytes expressed GalR1, whereas HSCs and hepatocytes expressed GalR2. Strategies were used to either stimulate or block GalR1 and GalR2 in FVB/N (wild-type) and Mdr2K0 mice and measure biliary hyperplasia and hepatic fibrosis by quantitative PCR and immunostaining of specific markers. Galanin treatment increased cholangiocyte proliferation and fibrogenesis in both FVB/N and Mdr2KO mice. Suppression of GalR1, GalR2, or both receptors in Mdr2K0 mice resulted in reduced bile duct mass and hepatic fibrosis. In vitro knockdown of GalR1 in cholangiocytes reduced $\alpha$-smooth muscle actin expression in LX-2 cells treated with cholangiocyte-conditioned media. A GalR2 antagonist inhibited HSC activation when Gal was administered directly to LX-2 cells, but not via cholangiocyte-conditioned media. These data demonstrate that Gal contributes not only to cholangiocyte proliferation but also to liver fibrogenesis via the coordinate activation of GalR1 in cholangiocytes and GalR2 in HSCs. (Am J Pathol 2020, 190: 586-601; https://doi.org/10.1016/j.ajpath.2019.10.023)
\end{abstract}

Galanin (Gal) is a 29-amino acid neuropeptide, distributed throughout the central and peripheral nervous system, with high concentrations in the amygdaloid nuclei, hypothalamus, locus coeruleus, and sacral spinal cord. ${ }^{1-4}$ Central Gal administration was found to stimulate the release of hypothalamic vasoactive intestinal peptide, resulting in pituitary secretion of prolactin and growth hormone via growth hormone releasing hormone. ${ }^{5-7}$ Galanin has been shown to colocalize with several neuromodulators, including growth hormone releasing hormone, substance $\mathrm{P}$, and vasoactive intestinal peptide, in the hypothalamus. Galanin is also expressed in the gastrointestinal tract, with highest concentration in the duodenum, and progressively lower abundance in the stomach, small intestine, and colon. ${ }^{8}$ Galanin was also identified in endocrine tissues, such as anterior pituitary and adrenal glands, being characterized as a neuroendocrine peptide. ${ }^{9}$

\footnotetext{
Supported by NIH R01 awards DK082435 and DK112803, US Department of Veterans Affairs Biomedical Laboratory Research and Development Service Merit award BX002638 (S.DeM.), the Veterans Health Administration, and the Central Texas Veterans Health Care System (Temple, TX).

Disclosures: None declared.

The contents do not represent the views of the US Department of Veterans Affairs or the US Government.
} 
Galanin regulates neuroendocrine signaling pathways that modulate food intake, especially fat intake and metabolism. ${ }^{10,11}$ Galanin exerts its actions through three types of receptors, known as Gal receptor 1 (GalR1), Gal receptor 2 (GalR2), and Gal receptor 3 (GalR3), which are G-protein-coupled receptors with different distribution throughout the body. ${ }^{12-15}$ Specifically, GalR1 is expressed in the basal forebrain, hypothalamus, and spinal cord, whereas GalR2 has a wider distribution in the brain, pituitary gland, and peripheral tissues. ${ }^{14-18}$ GalR3 is expressed at moderate levels only in discrete regions of the brain and at low levels in many central and peripheral tissues. ${ }^{18-20}$ GalR1 is expressed in cholangiocytes, where Gal is increased in experimental cholestasis, mediating cholangiocyte proliferation. ${ }^{21}$ All known Gal receptors are seven-transmembrane G-protein-coupled receptors with different G-protein coupling and signaling functions, contributing to the diversity of Gal-mediated effects. ${ }^{9}$ GalR1 signals through $\mathrm{G}_{\mathrm{i} / \mathrm{o}}$ protein, resulting in cAMP and cAMP responsive element binding protein signaling, whereas GalR2 can activate $G_{12 / 13}$ and $G_{q / 11}$ in addition to $G_{i / o} .{ }^{9}$

In the liver, a significant amount of $\mathrm{Gal}$ is produced and released into the systemic circulation during sympathetic nerve stimulation. ${ }^{22}$ Endogenous hepatic Gal acts directly on the liver to selectively modulate norepinephrine's metabolic action. ${ }^{23}$ We recently demonstrated that Gal stimulates cholangiocyte proliferation via GalR1-mediated extracellular signal-regulated kinase 1/2-ribosomal S6 kinase (RSK)-cAMP responsive element binding protein signaling pathway in a rodent model of cholestasis. ${ }^{21}$ However, the role of Gal signaling in fibrogenesis is unclear. Therefore, this study aims to assess the role of Gal and its receptors GalR1 and GalR2 in liver fibrosis in multidrug resistance protein 2 knockout (Mdr2KO) mice as a model of chronic hepatic inflammation and cholestasis and in vitro in LX-2 human hepatic stellate cells (HSCs).

\section{Materials and Methods}

\section{Chemicals, Kits, Antibodies, and Tissue Culture Media}

All chemicals were purchased from Millipore-Sigma (Burlington, MA), unless otherwise stated, and were of the highest grade available. Galanin Enzyme Immunoassay kit was purchased from Peninsula Laboratories International (San Carlos, CA). RNeasy kit for isolation of RNA from cells and tissue was from Qiagen (Frederik, MD). Galanin receptor 1 (GalR1) vivo-morpholino sequences for mouse (GalR1 sequence 1: 5'-TTCACCATAGCCAGTTCCA TCACTT- $3^{\prime}$; and sequence 2: 5'-AGTTGTGCCAGCCAGGGAAAACT- $\left.3^{\prime}\right)$ and a mismatch sequence $\left(5^{\prime}-\right.$ TTGAGCATACCCACTTCGATCCTT- $3^{\prime}$ ) were from Gene Tools (Philomath, OR). GalR1 siRNA, recombinant galanin (1 to 29), M617, AR-M, M871, and M40 were purchased from Tocris (Minneapolis, MN). Hematoxylin and VectaStain kits for immunohistochemistry (IHC) staining were from Vector Laboratories (Burlingame, CA). In IHC and immunofluorescence (IF) assays, the following antibodies from Abcam (Cambridge, MA) were used: Gal, cytokeratin (CK) 19, CK8, desmin, and $\alpha$-smooth muscle actin $(\alpha$-SMA). Culture media, including Dulbecco's modified Eagle's medium, minimal essential medium, and the supplements (ie, fetal bovine serum and penicillin/streptomycin) were from Gibco BRL, purchased through Thermo Fisher Scientific (Waltham, MA).

\section{Animal Experiments}

FVB/NJ (FVBN) and Mdr2KO mice were purchased from The Jackson Laboratory (Bar Harbor, ME) and maintained in a temperature-controlled environment at $20^{\circ} \mathrm{C}$ to $22^{\circ} \mathrm{C}$ with a 12:12-hour light-dark cycle, having free access to food and drinking water. All animal procedures were performed in accord with the guidelines of Baylor Scott \& White Health (Temple, TX) Institutional Animal Care and Use Committee, with approved protocols. In time-course experiments, 1-week-old, 1-month-old, 2-month-old, and 4-month-old male and female FVBN and Mdr2KO mice were used. In experiments designed to measure the effect of various agonists and antagonists of Gal receptors on liver fibrosis in Mdr2KO mice, 2-month-old male and female Mdr2KO mice, as well as age-matched FVBN mice as negative controls, were used. Four to five mice in each group of age/sex/type (FVBN or Mdr2KO) were used. In parallel, an equal number of 2-month-old male and female FVBN and Mdr2KO mice were treated with vehicle only (saline or $20 \%$ dimethyl sulfoxide). Galanin, M871, and M40 peptides were dissolved in saline or $20 \%$ dimethyl sulfoxide in saline, depending on their solubility, and administered by using Alzet osmotic minipumps (Cupertino, CA). Galanin, M871, and M40 were administered at a rate of $4 \mathrm{nmol} / \mathrm{kg}$ per day (mice weights being 25 to $30 \mathrm{~g}$ ). Vivomorpholino oligonucleotides, including two distinct sequences specific to mouse GalR1 and one mouse GalR1 mismatch control, were administered at a rate of 25 $\mu \mathrm{g} /$ mouse per day for 14 days, after which the mice were euthanized for blood and liver tissue collection.

\section{Assessment of mRNA Expression}

Assessment of gene expression at the mRNA level in liver tissue or cultured cells was performed by real-time quantitative PCR (qPCR) for Gal, GalR1, GalR2, CK19, $\alpha-S M A$, collagen type 1A1 (CollA1), metalloproteinase 2 (MMP2), and tissue inhibitor of metalloproteinase 1 (TIMP1). Fold changes in gene expression were normalized to glyceraldehyde-3-phosphate dehydrogenase and $\beta$-actin housekeeping genes. Total RNA was isolated by using RNeasy kit, followed by cDNA synthesis with iScript kit from BioRad Life Sciences (Hercules, CA) and qPCR using iTaq Universal SYBR-Green Supermix from the same company. $\mathrm{RT}^{2}$ qPCR Primer Assays were purchased from Qiagen Inc. 
(Germantown, MD). A thermal cycler AriaMax Real Time PCR system from Agilent Technologies (Santa Clara, CA) was used for running qPCR. The data were analyzed, as previously described. ${ }^{21}$ The $G a l$ and $C K 19$ mRNA expression in liver tissue of Mdr2KO and FVBN mice was correlated by correlation analysis. The correlation coefficient was calculated from the linear plot of the Gal mRNA fold change values versus CK19 mRNA fold change values.

\section{Assessment of Biliary Hyperplasia and Liver Fibrosis in Mdr2KO and FVBN Mice}

Biliary hyperplasia was assessed by measuring the intrahepatic biliary duct mass (IBDM) by IHC for CK19. Hepatic fibrosis markers, such as $\alpha$-SMA and desmin, were assayed by IHC of liver tissue from mice treated with GalR1 vivo-morpholino oligonucleotides or various agonists and antagonists of Gal receptors. Thus, for IHC, liver tissue sections $(4 \mu \mathrm{m}$ thick) were immunolabeled with primary antibodies specific to proteins of interest and then processed for staining with VectaStain kits. The IHC slides were scanned with a Leica SCN400 scanner (Leica Microsystems Inc., Buffalo Grove, IL) at $\times 20$ magnification, followed by screenshots at $\times 10$ magnification; and image analysis was performed with ImageJ software version 1.41 (NIH, Bethesda, MD; https://imagej.nih.gov/ij). For all samples and controls, the percentage areas of stained pixels were calculated and compared for significant differences. Liver samples were also assayed by using Sirius Red-specific staining of collagens I and III, which are increased in hepatic fibrosis, with the kit from IHC World (Ellicott City, MD).

\section{Assessment of Gal Concentration}

Galanin was assessed in serum and liver samples of Mdr2KO and FVBN mice, by using an enzyme-linked immunosorbent assay kit purchased from Peninsula Laboratories International (San Carlos, CA), according to the manufacturer's instructions.

\section{Assessment of Gal, GalR1, and GalR2 Expression in Liver by Laser-Capture Microdissection}

Frozen sections of liver ( $8 \mu \mathrm{m}$ thick) from 2 -month-old male and female FVBN and Mdr2KO mice were processed for IF by blocking of non-specific binding with $4 \%$ bovine serum albumin in phosphate-buffered saline (PBS) supplemented with $0.5 \%$ Tween 20 , followed by overnight incubation with 2 to $5 \mu \mathrm{g} / \mathrm{mL}$ primary antibody in PBS supplemented with $0.5 \%$ Tween 20/bovine serum albumin at $4^{\circ} \mathrm{C}$ and subsequent labeling with Alexa Fluor 488-conjugated secondary antibody incubation for 1 hour at room temperature. The liver sections were labeled with antibodies specific to CK19 marker of cholangiocytes, CK8 marker of hepatocytes, and desmin marker of HSCs. Subsequently, a Leica LMD7000 microdissection system
(Temple Health \& Bioscience District, Temple, TX) was used to isolate the specific liver cells. The RNA isolation from batches of 500 to 1000 cells was achieved using Arcturus PicoPure Frozen RNA Isolation kit from Thermo Fisher Scientific (Waltham, MA). The expression of $\mathrm{Gal}$ and its receptors GalR1 and GalR2 was then accomplished by the same procedure described for qPCR.

\section{Assessment of Gal Distribution in Different Types of Liver Cells by Confocal Microscopy}

The presence of Gal inside or on the surface of cholangiocytes, HSCs, and hepatocytes was studied by doublefluorescent labeling of liver frozen sections with a mix of antibodies specific to $\mathrm{Gal}$ and one of the three cell markers (ie, CK19 for cholangiocytes, CK8 for hepatocytes, and desmin for HSCs). The overlay of red fluorescence-labeled $\mathrm{Gal}$ with the green fluorescence-labeled cells was observed by using a confocal laser scanning system from Leica Microsystems Inc. (Buffalo Grove, IL).

\section{Assessment of Liver Enzymes, Creatinine, Blood Urea Nitrogen, and Creatine Kinase}

Serum alanine aminotransferase, aspartate aminotransferase, alkaline phosphatase, creatinine, blood urea nitrogen, and creatine kinase were measured using the IDEXX Catalyst One instrument from IDEXX Laboratories, Inc. (Houston, TX).

\section{Assessment of Cholangiocyte-Mediated Activation of HSCs in Culture}

In vitro experiments were run with mouse cholangiocytes and human LX-2 cells purchased from ATCC (Manassas, VA). The cells were grown according to the instructions from ATCC. In GalR1 knockdown experiments, the expression of GalRI mRNA was silenced in cholangiocytes by transfecting the cells with mouse GalRI-specific siRNA from OriGene (Rockville, MD), using Lipofectamine 2000 Reagent from Thermo Fisher Scientific (Waltham, MA), according to the manufacturer's instructions. Cholangiocytes or LX-2 cells were treated with the GalR1 and GalR2 agonists (Gal, $100 \mathrm{nmol} / \mathrm{L} ; \mathrm{M} 617,10$ $\mathrm{nmol} / \mathrm{L} ; \mathrm{AR}-\mathrm{M}, 10 \mathrm{nmol} / \mathrm{L} ; \mathrm{M} 871,100 \mathrm{nmol} / \mathrm{L} ; \mathrm{M} 40,10 \mathrm{nmol} /$ L) for 24 hours. After 24 hours, the conditioned media from cholangiocytes were used to treat a subset of LX-2 cells to determine the cross talk between cholangiocytes and LX-2 cells in HSC activation. The effect of GalR1 and GalR 2 agonists and antagonists on LX-2 cell activation was tested by measuring changes in $\alpha$-SMA and Col1A1 expression by qPCR and IF confocal microscopy. For IF, LX-2 cells grown on coverslips inside 6-well plates were fixed with $4 \%$ paraformaldehyde and blocked with $4 \%$ bovine serum albumin in PBS supplemented with $0.5 \%$ Tween 20 , followed by incubation with 2 to $5 \mu \mathrm{g} / \mathrm{mL}$ primary antibody in PBS supplemented with $0.5 \%$ Tween 20 overnight at $4{ }^{\circ} \mathrm{C}$ and subsequent labeling with $\mathrm{Cy} 3$-conjugated secondary antibody incubation for 1 hour at room temperature. 
After washings, coverslips were mounted in prolong Gold Antifade Mounting media with DAPI from Thermo Fisher Scientific (Waltham, MA).

\section{Statistical Analysis}

Quantifications by qPCR, enzyme-linked immunosorbent assay, and image analysis were analyzed by calculating the average and SEM of three replicates for each group of tested animals. The number of animals ( $n$ ) used for each treatment or as controls was four to five, and is specified in Results for each experiment. The statistical difference was calculated by using the $t$-test, and was considered significant when $P<0.05$. When multiple groups of animals were compared, the two-way analysis of variance, followed by an appropriate post-hoc test with GraphPad Prism software version 6.0 (San Diego, CA), was used.

\section{Results}

Time Course of Gal Expression in the Liver of Mdr2KO Mice Positively Correlates with CK19 Expression

Gal and CK19 mRNA expression were assessed in livers of male and female FVBN and Mdr2KO mice from 1 week to
4 months of age. Gal mRNA was more abundant in Mdr2KO mice than in FVBN controls at all time points tested, and the highest levels were detected at the age of 2 months for male and female Mdr2KO mice (Figure 1A). In both FVBN and Mdr2KO mice, Gal mRNA increased with age up to 2 months, then regressed at 4 months. Interestingly, when the mRNA of CK19 was assessed in the same liver samples, a similar pattern of expression was found (Figure 1B). There was a slow and minimal increase of CK19 mRNA in FVBN mice over time, up to 2 months, and a regression afterward, with no sex-related differences. In Mdr2KO mice, CK19 expression was greater than in FVBN mice at every tested time point, and it followed the same pattern as in FVBN mice, increasing up to 2 months and then decreasing by 4 months of age. For both $\mathrm{Gal}$ and $C K 19$, the mRNA expression was significantly higher in females than in males at 2 months of age. Because Mdr2KO mice have been characterized with a period of biliary hyperplasia, followed by ductopenia, the expression of $\mathrm{Gal}$ and $C K 19$ was correlated in livers of FVBN and Mdr2KO mice (Figure 1C). A positive correlation was found between Gal and CK19 expression regardless of genotype, age, or sex, with a correlation coefficient of 0.8545 . To confirm these data, Gal peptide concentration was assayed in the
A

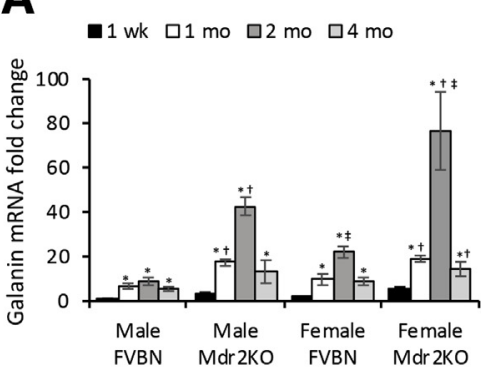

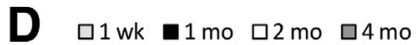

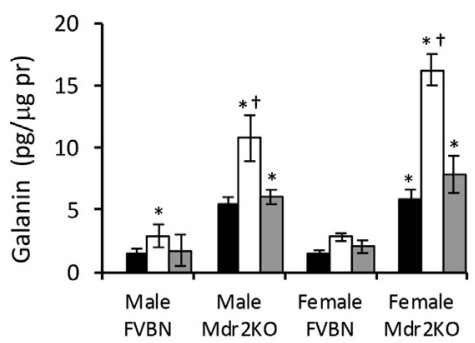

B

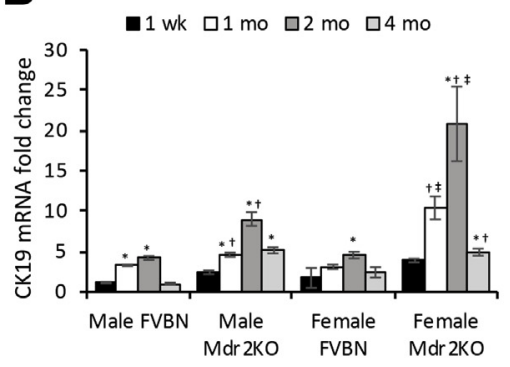

$\mathbf{E}$

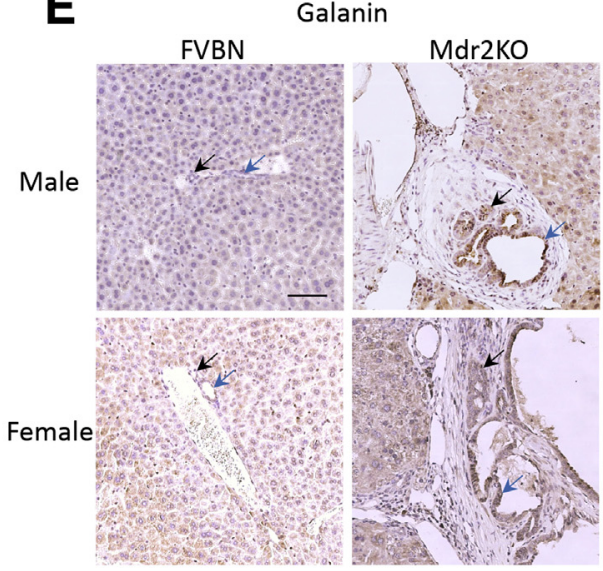

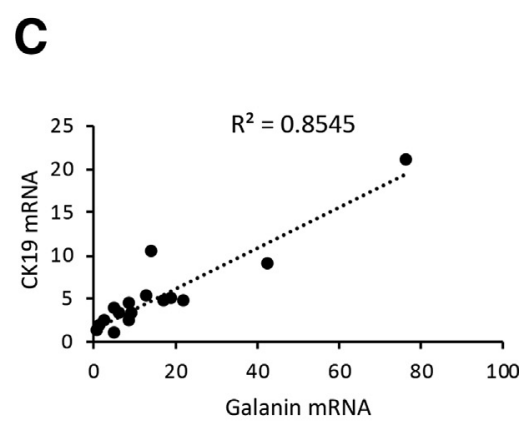

$\mathbf{F}$

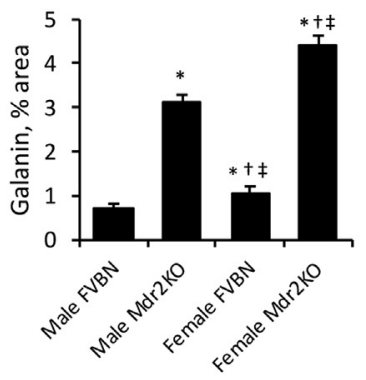

Figure 1 Time course of Gal and cytokeratin 19 (CK19) expression in the liver of Mdr2K0 versus FVBN mice. A and B: mRNAs of Gal (A) and CK19 marker of cholangiocytes (B) were assessed by real-time quantitative PCR in liver of male and female FVBN and Mdr2KO mice from 1 week to 4 months of age. C: Linear correlation plot of CK19 mRNA versus Gal mRNA in FVBN and Mdr2KO mice at 1 week to 4 months of age. D: Galanin concentration in liver of FVBN and Mdr2KO mice, at 1 week, 1 month, 2 months, and 4 months of age. E: Galanin immunohistochemistry (IHC) in the liver of 2-month-old male and female FVBN and Mdr2KO mice. Black arrows indicate small bile ducts; blue arrows, large bile ducts. F: Bar plot of Gal expression measured as area percentage of stained pixels in IHC images of Gal in E. $n=4$ (A, B, D and F). ${ }^{*} P<0.051,2$, and 4 months versus 1 week; ${ }^{\dagger} P<0.05$ Mdr2K0 versus FVBN; ${ }^{\ddagger} P<0.05$ female versus males. Scale bar $=100 \mu \mathrm{m}(\mathrm{E})$. 
liver of male and female FVBN and Mdr2KO mice (Figure 1D). The peptide was not detected in liver from 1 -week-old mice, but it reached levels of 1 to $16 \mathrm{pg} / \mu \mathrm{g}$ protein in older mice, with the highest concentrations observed in 2-month-old Mdr2KO mice. At all tested time points, Gal concentration in the liver was greater in Mdr2KO mice than in FVBN controls, indicating a significant increase in hepatic $\mathrm{Gal}$ associated with cholestasis in Mdr2KO mice. Galanin assay by IHC demonstrated a remarkable increase in Gal-specific staining in Mdr2KO mice compared with FVBN mice (Figure 1E), with immunoreactivity found predominantly in cholangiocytes. Image analysis of Gal IHC staining confirmed a significant increase in Gal in liver of Mdr2KO mice compared with FVBN mice (Figure 1F).

\section{Distribution of Gal and Its Receptors GalR1 and GalR2 in Hepatic Cells}

Because Gal is commonly considered to be synthesized exclusively in central or peripheral parts of the nervous system, and the notion of $\mathrm{Gal}$ being produced in liver cells is new, ${ }^{21}$ Gal mRNA expression was studied in cholangiocytes, HSCs, and hepatocytes by dissecting CK19-, desmin-, and CK8-positive cells, respectively, using lasercapture microdissection. The $\Delta \mathrm{Ct}$ values (which is defined as the $\mathrm{Ct}$ value of the target gene minus the $\mathrm{Ct}$ value of the housekeeping gene) of Gal, GalR1, and GalR2 versus $\beta$-actin, shown in Supplemental Table S1, suggest that cholangiocytes expressed GalR1 > Gal $>>$ GalR2, whereas hepatocytes and HSCs expressed GalR2 $>>$ Gal or GalR1. The fold change values of the mRNAs of these genes were also calculated (Figure 2), indicating that GalRl mRNA is expressed mostly in cholangiocytes, whereas GalR2 mRNA is predominantly expressed in hepatocytes and HSCs (Figure 2).

The distribution of Gal in various types of cells within the liver was also investigated by IF and confocal microscopy (Figure 3). Galanin was more abundant in liver of male and female Mdr2KO mice than in FVBN controls (Figure 3).
Colocalization of Gal with CK19 indicated that Gal was present in the cholangiocytes (Figure 3A). In Mdr2KO mice, Gal also colocalized with desmin, a marker of HSCs (Figure 3B), and with CK8 marker of hepatocytes (Figure 3C), demonstrating that $\mathrm{Gal}$ is associated with these cells, which had been shown to express Gal receptors by laser-capture microdissection (Figure 2).

\section{GalR1 Vivo-Morpholino Treatment of Mdr2KO Mice Reduces IBDM and Liver Fibrosis}

To further explore the function of GalR1 in hepatic cholestasis, FVBN and Mdr2KO mice were administered GalR1specific vivo-morpholino sequences to reduce expression of this particular Gal receptor, which is expressed in intrahepatic cholangiocytes. The IBDM was then assessed by qPCR (Supplemental Figure S1A) and IHC of cholangiocyte marker CK19 (Figure 4, A and B). Both GalRI vivo-morpholino sequences significantly reduced CK19 mRNA and CK19 protein in male and female Mdr2KO mice compared with mismatch vivo-morpholino-treated mice (Supplemental Figure S1A and Figure 4, A and B). The proliferating cell nuclear antigen (PCNA) marker of cell proliferation was significantly reduced in $\mathrm{Mdr} 2 \mathrm{KO}$ mice treated with GalRl-specific vivo-morpholino compared with Mdr2KO mice treated with the mismatch control sequence (Supplemental Figure S1B).

At the mRNA level, the expression of fibrosis markers $\alpha$-SMA, Col1A1, MMP2, and TIMP1 was down-regulated in male and female Mdr2KO mice treated with GalR1specific vivo-morpholino, compared with mismatch-treated controls (Supplemental Figure S1, C-F). However, the inhibitory effect of GalR1 vivo-morpholino sequences was smaller for $\alpha$-SMA and Col1A1 fibrotic markers than for CK19 and PCNA markers of cholangiocyte proliferation (Supplemental Figure S1). The protein expression of desmin (Figure 4, C and D), $\alpha$-SMA (Figure 4, E and F), and collagens I and III (Figure 4, G and H) was also measured and indicated a significant decrease of these fibrotic markers in Mdr2KO mice treated with GalR1 vivo-morpholino
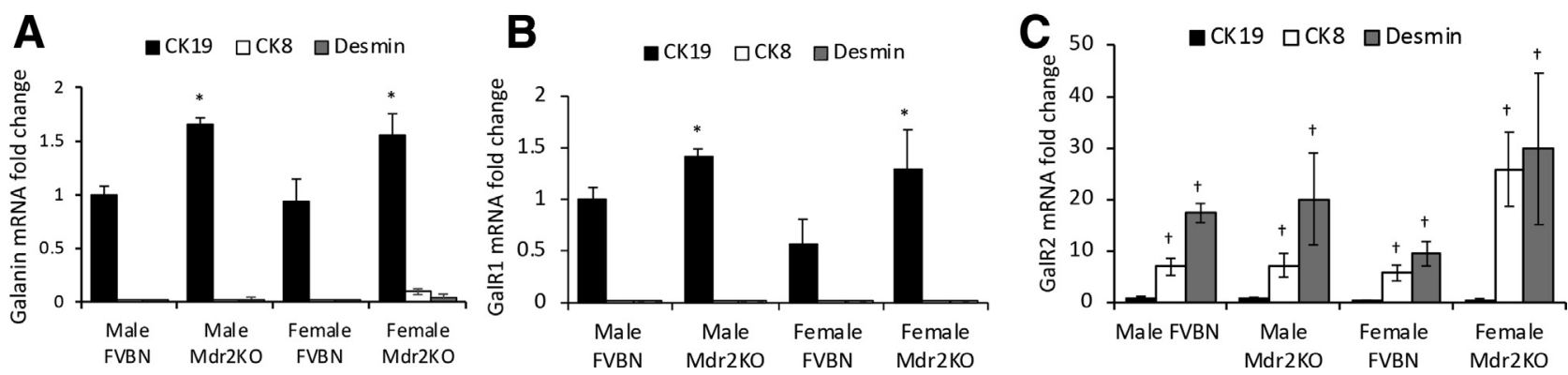

Figure 2 Expression of Gal and its receptors GalR1 and GalR2 in cholangiocytes, hepatic stellate cells (HSCs), and hepatocytes in liver of FVBN and Mdr2KO mice by laser-capture microdissection (LCM). Liver sections from male and female FVBN and Mdr2KO mice, 2 months of age, were processed by LCM. A: Relative expression of Gal mRNA in cytokeratin (CK) 19-immunolabeled cholangiocytes, CK8-immunolabeled hepatocytes, and desmin-immunolabeled HSCs. B: Relative expression of GalR1 mRNA in CK19-, CK8-, and desmin-immunolabeled cells. C: Relative expression of GalR2 mRNA in CK19-, CK8-, and desminimmunolabeled cells. $n=4$ (A-C). ${ }^{*} P<0.05$ Mdr2K0 versus FVBN; ${ }^{\dagger} P<0.05$ CK8 or desmin versus CK19. 
A

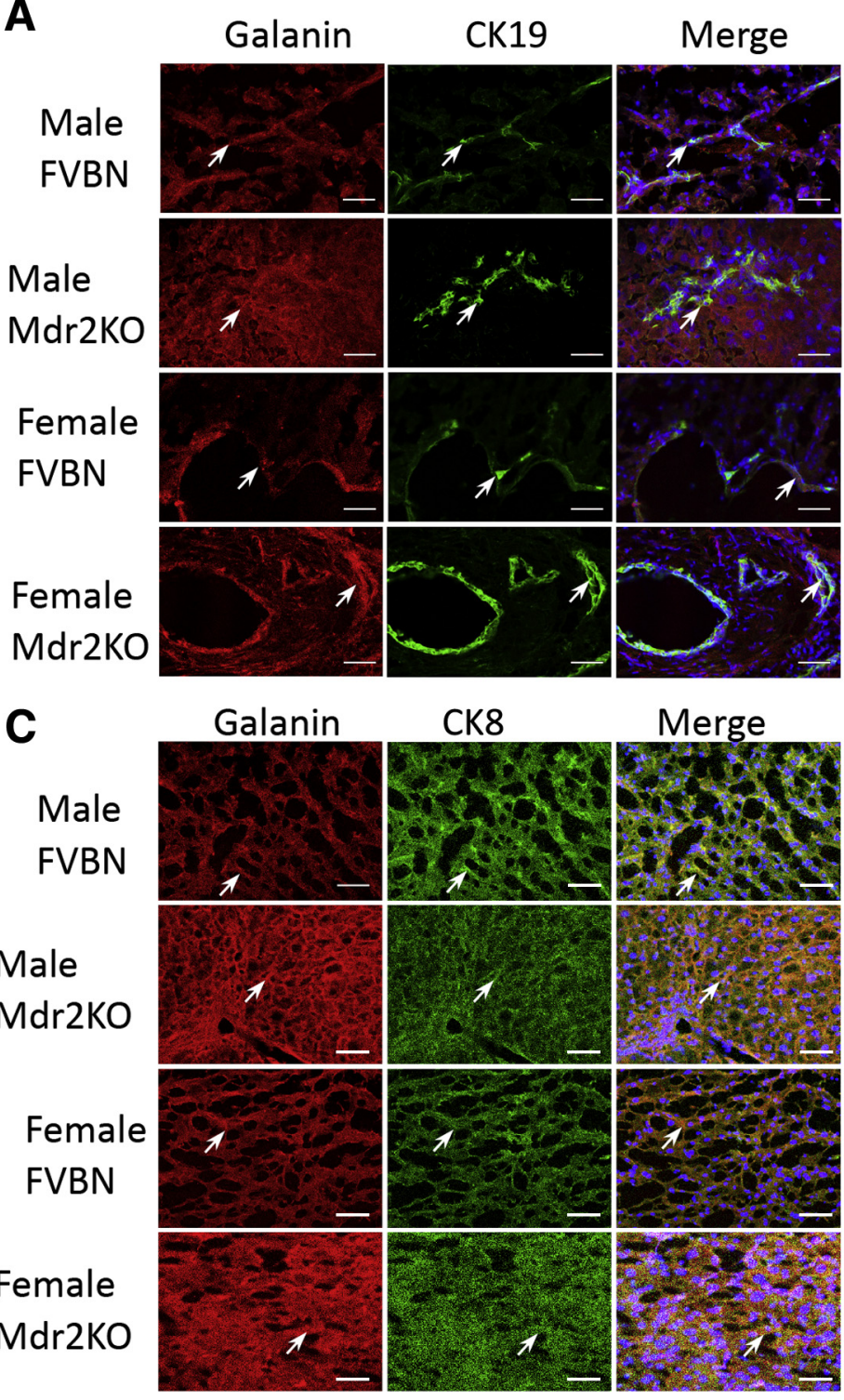

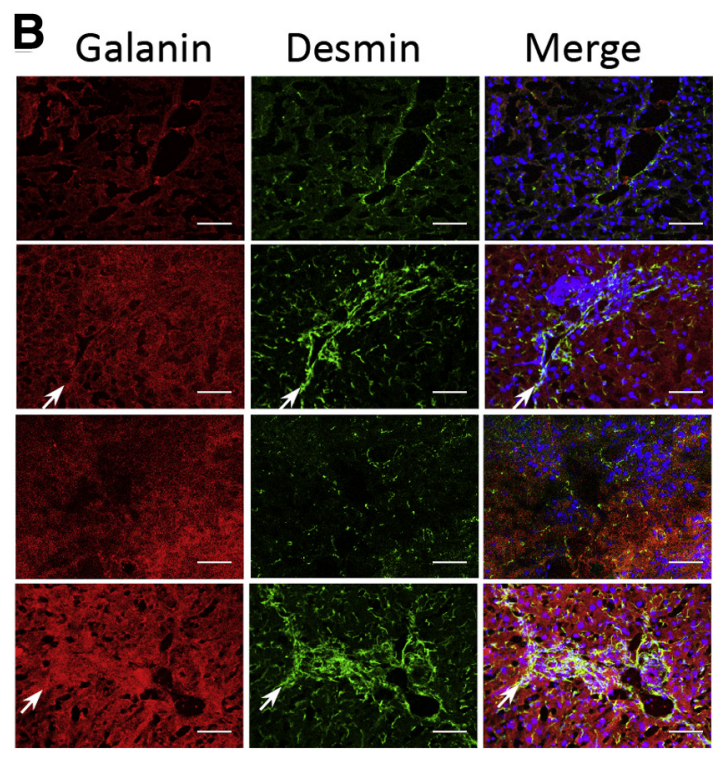

Figure 3 Colocalization of Gal with markers of cholangiocytes, hepatic stellate cells (HSCs), and hepatocytes in liver of FVBN and Mdr2KO mice. Liver sections from 2-month-old FVBN and Mdr2KO mice were immunolabeled and imaged by confocal microscopy to determine Gal distribution in cholangiocytes [cytokeratin (CK) 19; A], HSCs (desmin; B), or hepatocytes (CK8; C). Galanin is shown in red; CK19, CK8, and desmin are in green; and the overlapping pixels are shown in yellow. Arrows point to cells that express both Gal and the respective, specific cell marker. Scale bars $=$ $100 \mu \mathrm{m}(\mathbf{A}-\mathbf{C})$. compared with mismatch-treated mice. Desmin was found to be the least affected by GalR1 vivo-morpholinos (Figure 4D). These data support that the effect of GalR1 vivo-morpholino sequences were smaller for fibrosis markers than for cholangiocyte markers, suggesting that GalR1 is critical in Gal-induced biliary hyperplasia and, to a lesser extent, in Gal-induced fibrogenesis.

\section{GalR2-Specific Antagonist M871 Alleviates Liver} Fibrosis in Mdr2KO Mice without Changing IBDM

To assess the role of GalR2 in Gal-induced cholangiocyte proliferation, male and female $\mathrm{Mdr} 2 \mathrm{KO}$ and FVBN mice were treated with vehicle or M871, a GalR2-specific antagonist. The data indicate that M871 did not affect CK19 or PCNA mRNA expression in male or female
Mdr2KO mice (Supplemental Figure S2, A and B). The same results were obtained when assessing CK19 protein expression (Figure 5, A and B).

$\alpha$-SMA, CollA1, MMP2, and TIMP1 mRNAs were down-regulated in Mdr2KO mice treated with M871 (Supplemental Figure S2, C-F). At protein level, desmin was significantly decreased in Mdr2KO mice as a result of treatment with GalR2 antagonist M871 (Figure 5, C and D). The assessment of $\alpha$-SMA (Figure 5, E and F), and of collagen types I and III by Sirius Red staining (Figure 5, G and $\mathrm{H}$ ), confirmed that M871 was able to reduce hepatic fibrosis in Mdr2KO mice. The results indicate that inhibition of GalR2 is conducive to a significant reduction of hepatic fibrosis markers in Mdr2KO mice compared with mice treated with vehicle only, while not having any effect on biliary hyperplasia. 


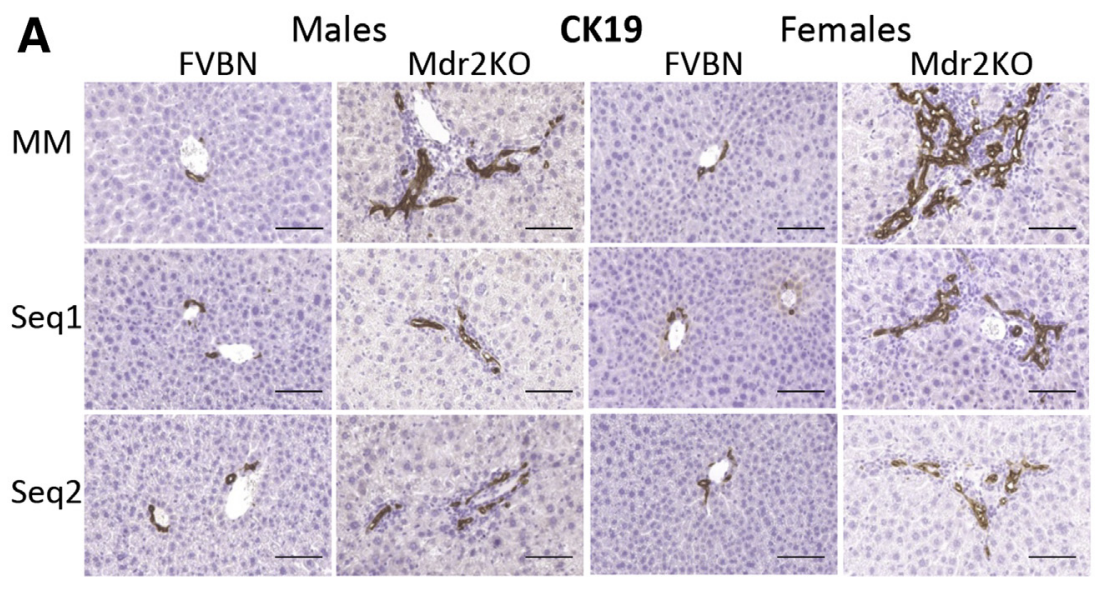

B
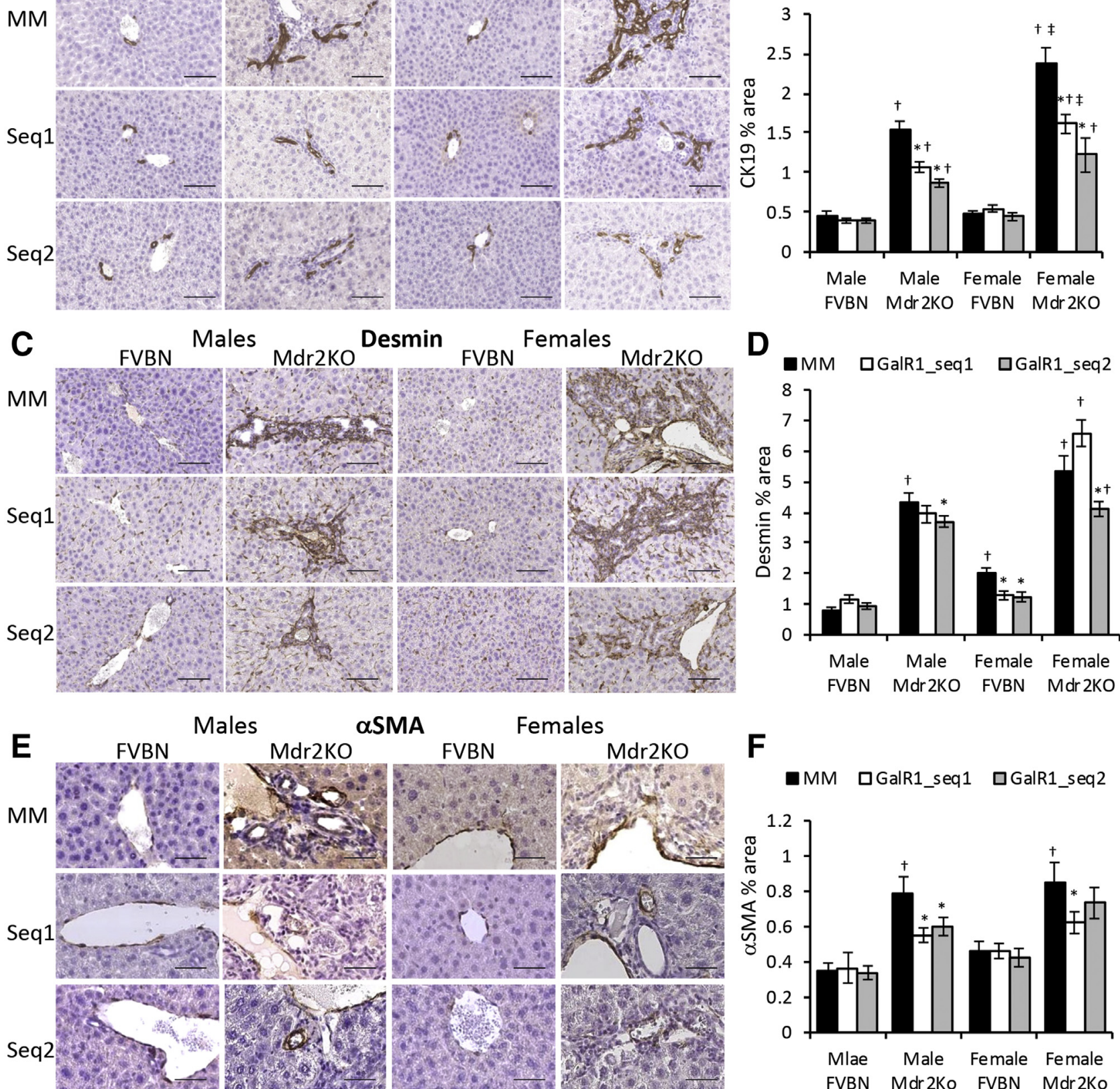

F

-MM QGalR1_seq1 QGalR1_seq2
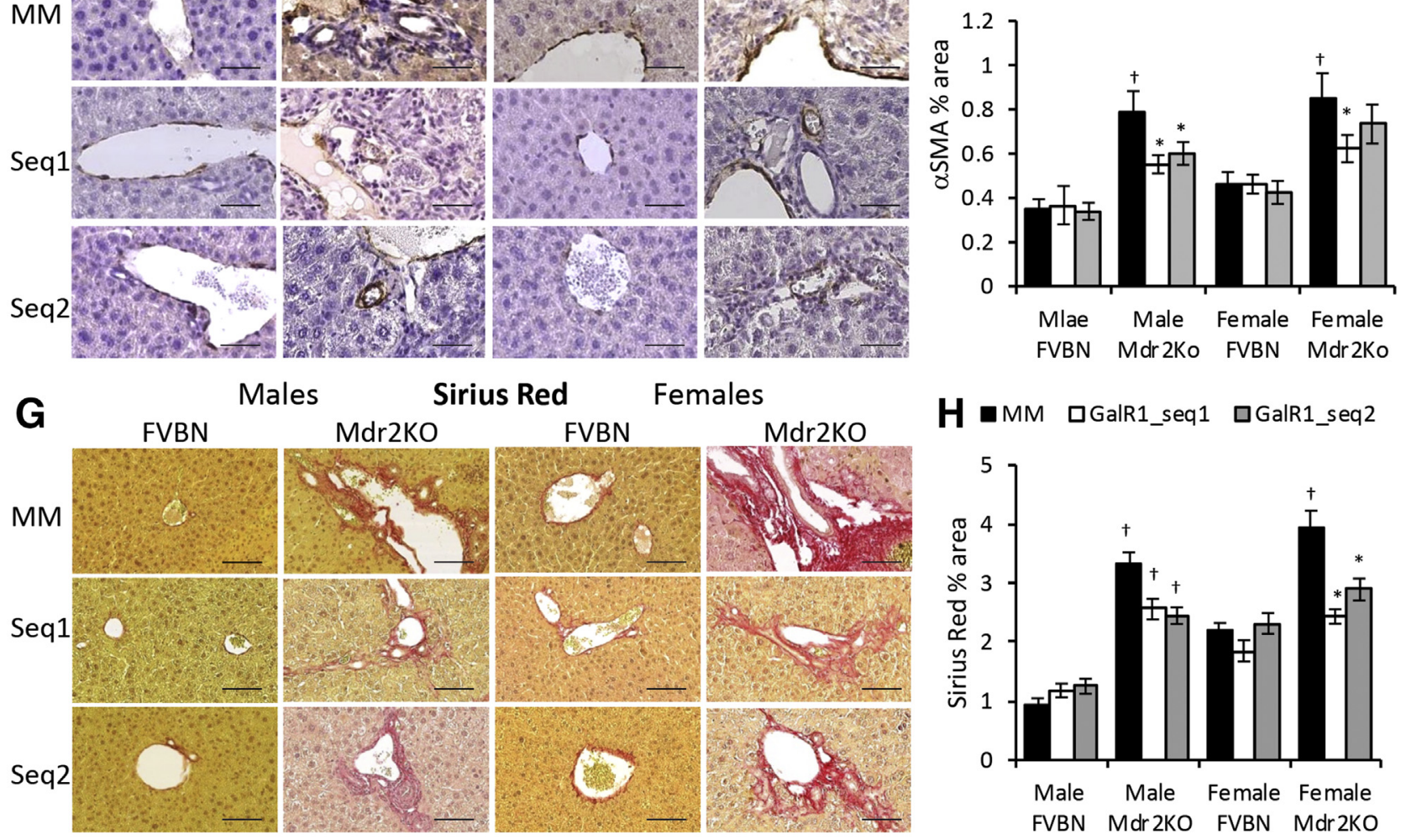

H $\square M M$ QGalR1_seq1 aGalR1_seq2

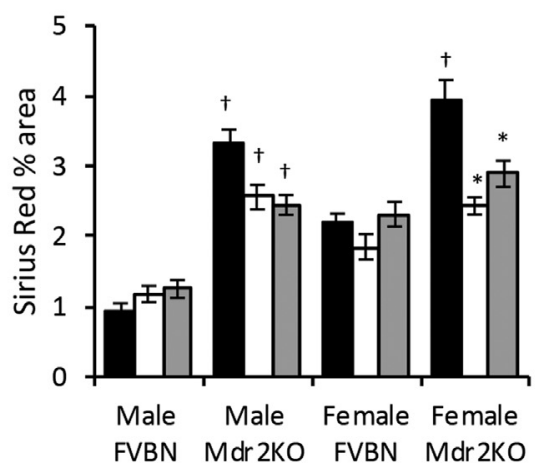


An Antagonist of Both GalR1 and GalR2 Reduces Cholangiocyte Proliferation and Hepatic Fibrosis in Mdr2KO Mice

M40, a non-specific antagonist of GalR1 and GalR2, was used to test the role of these receptors on Gal-induced biliary hyperplasia and hepatic fibrosis. M40 treatment caused a significant down-regulation of CK19 and PCNA mRNAs in Mdr2KO mice (Supplemental Figure S3, A and B). Further experiments to determine changes in CK19 protein expression showed that treatment with M40 resulted in strong reduction of IBDM in Mdr2KO mice (Figure 6, A and B) when compared with Mdr2KO mice treated with vehicle.

Expression of fibrogenesis markers, including $\alpha$-SMA, CollA1, MMP2, and TIMP1, at mRNA level was also down-regulated in $\mathrm{Mdr} 2 \mathrm{KO}$ mice treated with M40 (Supplemental Figure S3, C-F). Protein expression of fibrosis-related genes, including desmin (Figure 6, $\mathrm{C}$ and D), $\alpha$-SMA (Figure 6, E and F), and collagens I and III (Figure 6, G and $\mathrm{H}$ ), confirmed that M40 treatment of Mdr2KO mice resulted in a significant reduction of hepatic fibrosis. The results indicated that M40 decreased both cholangiocyte proliferation and hepatic fibrogenesis in Mdr2KO mice.

\section{Antagonists of Gal Receptors Reduce Systemic Gal and Liver Enzymes in Mdr2KO Mice}

Serum concentrations of Gal were measured in FVBN and Mdr2KO mice that had been treated with M871 or M40 versus vehicle only (Figure 7). The results suggest that these antagonists of Gal receptors caused a modest but significant alleviation of the abnormally high levels of Gal in Mdr2KO mice. All tested liver enzymes were elevated in Mdr2KO mice compared with FVBN controls (Supplemental Table S2). However, alanine aminotransferase, aspartate aminotransferase, and ALPK were reduced in Mdr2KO mice treated with GalR1 vivomorpholino, M871, or M40, compared with vehicletreated $\mathrm{Mdr} 2 \mathrm{KO}$ mice.

\section{Nonhepatic Effects of Gal Receptor Antagonists in FVBN and Mdr2KO Mice}

To investigate possible adverse effects of GalR antagonists on vital organs other than the liver, blood biomarkers of the heart (creatine kinase) and kidneys (creatinine and blood urea nitrogen) were assessed in FVBN and Mdr2KO mice when treated with GalR1 vivo-morpholino, M871, and M40, compared with vehicle-treated mice. The suppression of Gal receptors had no effects on the heart or kidneys (Supplemental Table S3).

\section{Effect of Galanin on IBDM and Hepatic Fibrosis}

Mdr2KO and FVBN mice treated with vehicle or Gal were tested for the expression of CK19 (Supplemental Figure S4) and fibrosis (Supplemental Figure S5) at mRNA and protein level. In Mdr2KO mice, Gal increased IBDM slightly in males but not in females, whereas a significant increase in CK19 mRNA and protein was detected in all FVBN mice treated with Gal over nontreated controls (Supplemental Figure S4). Similarly, fibrosis biomarkers $\alpha$-SMA, Col1A1, MMP2, and TIMP1 were increased more in FVBN than in Mdr2KO mice by Gal treatment (Supplemental Figure S5). Galanin differentially affected the expression of various genes involved in fibrosis progression. Thus, it increased desmin and $\alpha$-SMA in FVBN mice only while it stimulated expression of collagens I and III, in both FVBN and $\mathrm{Mdr} 2 \mathrm{KO}$ mice.

\section{GalR1 Expression in Cholangiocytes in Vitro Is Essential for Gal-Induced Activation of HSCs}

Mouse cholangiocytes were transfected with two sequences of GalR1-specific siRNA, and the reduction of GalR1 expression in these cells was successful, as confirmed by GalR1 qPCR (Figure 8A).

LX-2 cells were incubated with conditioned media from cholangiocytes in which GalR1 was knocked down, versus negative control (cholangiocytes transfected with scramblesiRNA), in the absence or presence of agonists specific to GalR1 (M617), GalR2 (AR-M), or both (Gal); the activation of LX-2 HSCs was then measured by qPCR for $\alpha$-SMA and Col1A1 (Figure 8, B and C). Both fibrosis markers were upregulated by $\mathrm{Gal}$ and $\mathrm{M} 617$ but not AR-M in positive controls (ie, LX-2 cells treated with media from nontransfected cholangiocytes or from cholangiocytes transfected with scramble-siRNA). However, there was no increase in $\alpha$-SMA and CollA1 mRNAs in LX-2 cells incubated with media from cholangiocytes transfected with GalR1 siRNAs and stimulated with Gal, M617, or AR-M treatments (Figure 8, B and $\mathrm{C}$ ). These results suggest that activation of LX-2 cells with cholangiocyte-conditioned

\footnotetext{
Figure 4 Knockdown of GalR1 with vivo-morpholino reduces intrahepatic biliary duct mass (IBDM) in Mdr2K0 mice. Two-month-old male and female Mdr2K0 mice and FVBN controls were treated with GalR1 vivo-morpholino sequence 1 (GalR1-seq1) or 2 (GalR1-seq2), or with mismatched negative control sequence (MM), and tested for IBDM hyperplasia and hepatic fibrosis markers, by immunohistochemistry (IHC). A: Representative images of cytokeratin (CK) 19 IHC in livers of mice treated with MM, GalR1-seq1, and GalR1-seq2. B: Quantification of CK19 IHC by image analysis. C: Images of desmin IHC in liver from FVBN and Mdr2KO mice treated with vivo morpholino sequences. D: Quantification of desmin expression. E: Representative images of $\alpha$-smooth muscle actin $(\alpha-S M A)$ IHC. F: Quantification of $\alpha$-SMA expression by image analysis. G: Representative images of Sirius Red staining of liver sections from mice treated with vivo-morpholinos for GalR1 or MM. H: Quantifications of Sirius Red staining of collagen I and II from images in G. $n=4(\mathbf{B}, \mathbf{D}, \mathbf{F}$ and $\mathbf{H})$. ${ }^{\star} P<0.05$ GalR1 vivomorpholino versus MM; ${ }^{\dagger} P<0.05$ Mdr2K0 versus FVBN; ${ }^{\ddagger} P<0.05$ male versus female. Scale bars: $100 \mu \mathrm{m}(\mathbf{A}, \mathbf{C}$, and $\mathbf{G}) ; 50 \mu \mathrm{m}(\mathbf{E})$.
} 

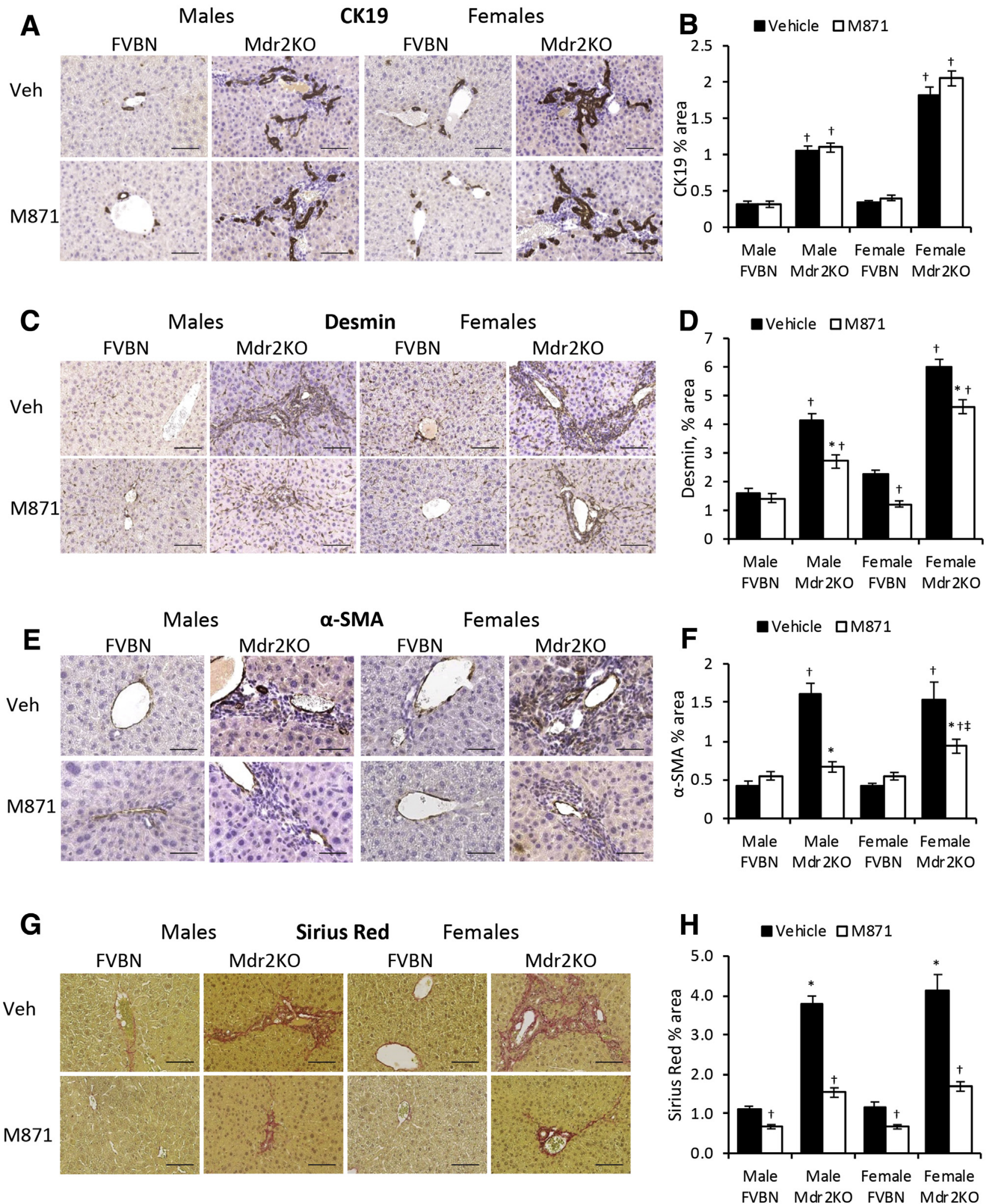

Figure 5 GalR2 antagonist M871 alleviates hepatic fibrosis in Mdr2K0 mice. Two-month-old male and female Mdr2K0 and FVBN mice were treated with M871, a GalR2-specific antagonist, and tested for intrahepatic biliary duct mass hyperplasia and hepatic fibrosis markers. A: Representative images of cytokeratin (CK) 19 immunohistochemistry (IHC). B: Quantification of CK19 protein by image analysis. C: Representative images of desmin IHC. D: Quantification of desmin. E: Images of $\alpha$-smooth muscle actin ( $\alpha$-SMA) IHC. F: Quantification of $\alpha$-SMA by image analysis. G: Representative images of Sirius Red-stained collagen I and III. H: Image analysis and quantification of Sirius Red percentage area in liver sections from mice treated with vehicle (Veh) or M871. $n=4$ (B, D, F and $\mathbf{H}) .{ }^{*} P<0.05$ M871 versus vehicle; ${ }^{\dagger} P<0.05$ Mdr2K0 versus FVBN; ${ }^{\ddagger} P<0.05$ male versus female. Scale bars: $100 \mu \mathrm{m}(\mathbf{A}, \mathbf{C}$, and $\mathbf{G})$; $50 \mu \mathrm{m}(\mathbf{E})$. 
A

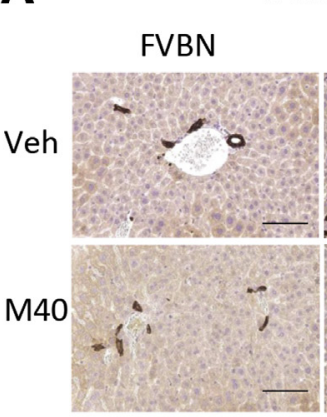

CK19

$\mathrm{Mdr} 2 \mathrm{KO}$

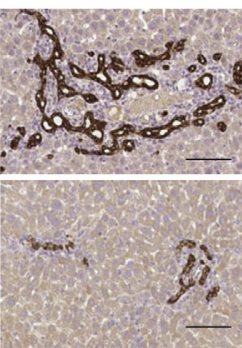

Females

FVBN

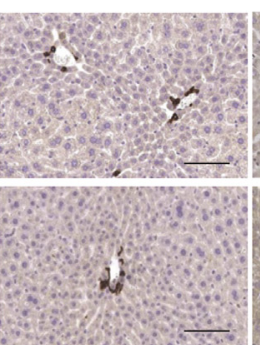

Mdr2KO

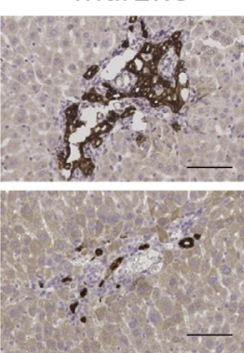

B

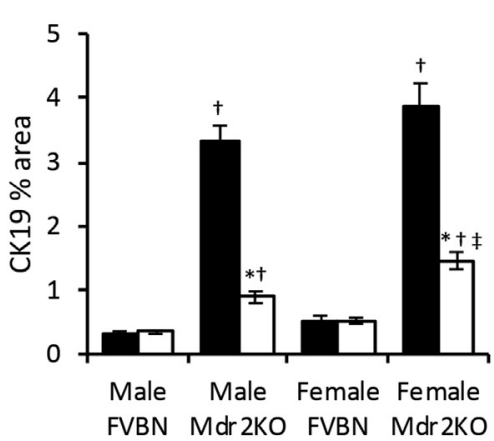

C
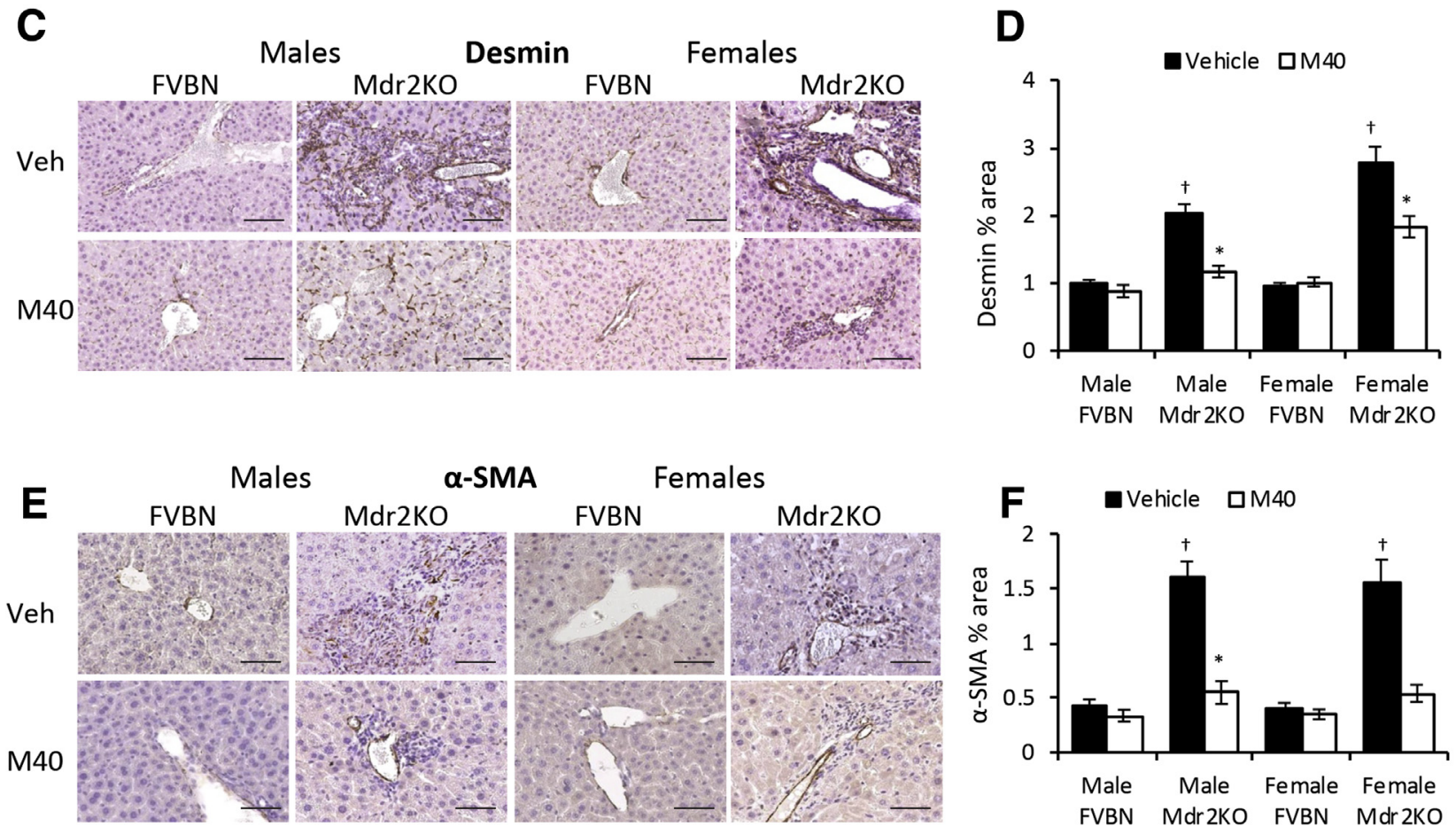

G

Males

Sirius Red

Females
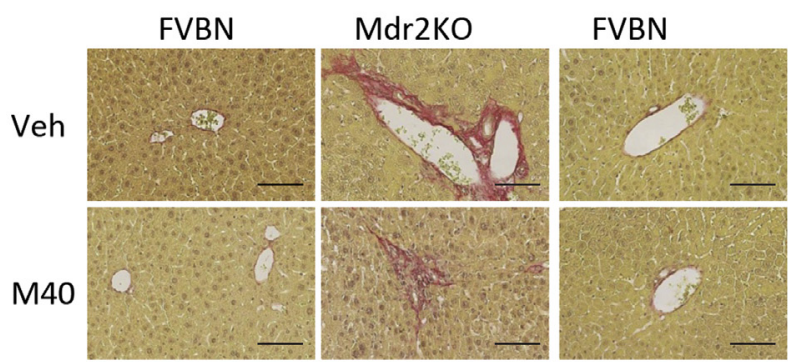

Mdr2KO
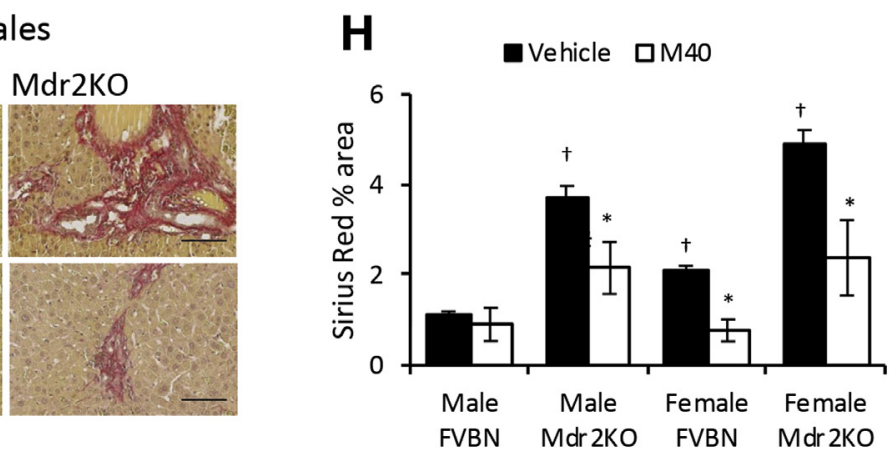

Figure 6 Galanin receptor pan-antagonist M40 reduces biliary hyperplasia and hepatic fibrosis in Mdr2KO mice. Two-month-old male and female Mdr2KO and FVBN mice were treated with M40, a non-specific antagonist of GalR1 and GalR2, and tested for intrahepatic biliary duct mass hyperplasia and hepatic fibrosis markers. A: Representative images of cytokeratin (CK) 19 immunohistochemistry (IHC). B: Quantification of CK19 by image analysis. C: Images of desmin IHC in mice treated with vehicle (Veh) or M40. D: Quantification of desmin staining. E: IHC images of $\alpha$-smooth muscle actin ( $\alpha$-SMA) in liver of mice treated with vehicle or M40. F: Quantification of $\alpha$-SMA expression based on image analysis. G: Images of Sirius Red staining of collagen I and III in liver of mice treated with vehicle or M40. H: Quantification of Sirius Red-stained collagen I and III in liver of mice treated with vehicle or M40. $n=4(\mathbf{B}, \mathbf{D}, \mathbf{F}$ and $\mathbf{H})$. ${ }^{\star} P<0.05$ M40 versus vehicle; ${ }^{\dagger} P<0.05$ Mdr2K0 versus FVBN; ${ }^{\ddagger} P<0.05$ male versus female. Scale bars $=100 \mu \mathrm{m}(\mathbf{A}, \mathbf{C}, \mathbf{E}$, and $\mathbf{G})$. 


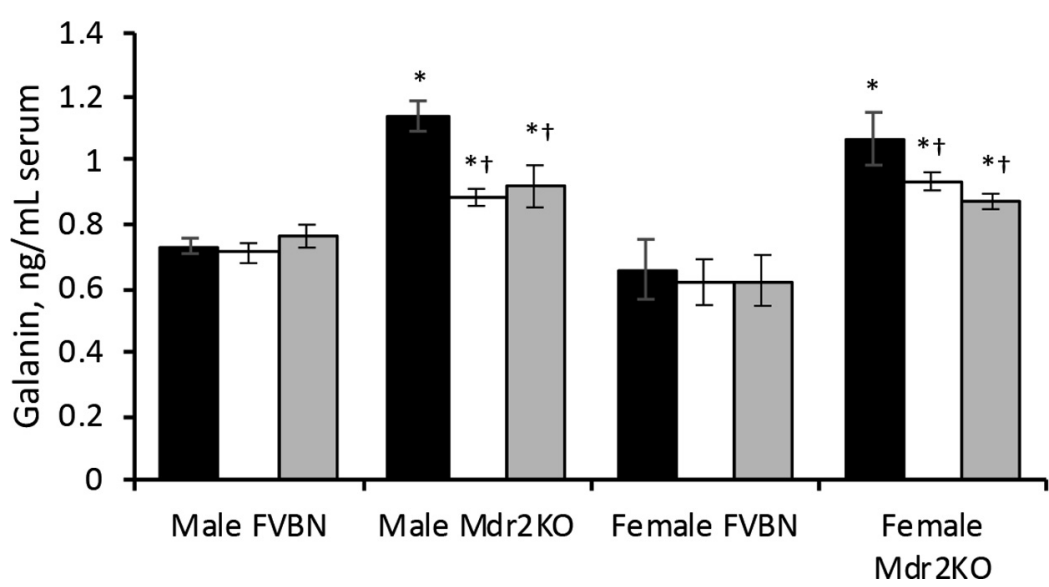

Figure 7 GalR1 and GalR2 antagonists alleviate serum level of Gal in Mdr2KO mice. Gal concentration in serum from FVBN and Mdr2K0 mice treated with vehicle, M871, or M40 was assessed by enzyme immunoassay. $n=4$ (). ${ }^{*} P<0.05$ Mdr2KO versus FVBN mice; ${ }^{\dagger} P<0.05$ M871/M40 versus vehicle. media is possible only when GalR1 is functional in cholangiocytes.

\section{GalR2 Is Critical for LX-2 Cell Activation by Gal Directly or via Cholangiocyte-Conditioned Media}

The role of GalR2 was investigated in the activation of LX2 cells when stimulated directly or through conditioned media, via cholangiocytes treated with Gal or specific agonists of GalR1 and GalR2 (Figure 9). Thus, $\alpha$-SMA and Col1A1 were assessed in LX-2 cells that were treated with vehicle, Gal, GalR1 agonist M617, or GalR2-specific agonist AR-M directly or via cholangiocyte-conditioned media. Both markers were up-regulated by $\mathrm{Gal}$ and GalR2-specific agonist when incubated directly with these peptides compared with LX-2 cells treated with vehicle (Figure 9, A and B). However, $\alpha$-SMA and Col1A1 were up-regulated in LX-2 cells when incubated with media from cholangiocytes stimulated by $\mathrm{Gal}$ and GalR1-specific agonist M617 but not by GalR2-specific agonist AR-M (Figure 9, A and B).

In another set of experiments, LX-2 cells were incubated with conditioned media from cholangiocytes treated with GalR2-specific antagonist M871, versus vehicle as negative control, then tested for $\alpha$-SMA and CollAl mRNA expression (Figure 9, C and D). The data demonstrated that stimulation of cholangiocytes by $\mathrm{Gal}$ was insufficient for further activation of LX-2 cells when GalR2 was blocked in LX-2 cells by M871 antagonist. The up-regulation of $\alpha$ SMA mRNA in LX-2 cells, when treated with Gal in the absence or presence of GalR2 antagonist M871 directly or via cholangiocyte-conditioned media, was tested at protein level by IF (Figure 9, E and F). $\alpha$-SMA expression was increased when LX-2 cells were incubated with Gal or with media from Gal-treated cholangiocytes. In contrast, in the presence of M871, Gal did not induce $\alpha$-SMA expression in LX-2 cells directly or via cholangiocyte-conditioned media.
Finally, the effect of M40, a non-specific antagonist of both GalR1 and GalR2, was tested on cholangiocytemediated activation of LX-2 cells (Figure 10). None of the GalR1 or GalR2 agonists was able to induce up-regulation of $\alpha$-SMA or Col1A1 when LX-2 cells were treated with M40 (Figure 10A) or with conditioned media from cholangiocytes treated with M40 (Figure 10B).

\section{Discussion}

The role of Gal and its receptors GalR1 and GalR2, in modulating biliary hyperplasia and fibrogenesis, was investigated. The Mdr2KO mouse is an established experimental model to study hepatic inflammation and cholestasis, and is widely used to investigate the initiation and progression of cholestasis. ${ }^{24,25}$ When assessing the time course of Gal mRNA expression, at all tested time points, the expression of Gal in the liver was significantly greater in Mdr2KO mice than in FVBN controls. Interestingly, there was a strong correlation between $\mathrm{Gal}$ and CK19 expression, suggesting that $\mathrm{Gal}$ has a role in the neuroendocrine regulation of cholangiocyte proliferation in hepatic cholestasis. These results confirm previously published data demonstrating that $\mathrm{Gal}$ induces cholangiocyte proliferation in bile duct-ligated rats. ${ }^{21}$ In Mdr2KO mice, which expressed an abnormally high level of Gal, the treatment with exogenous $\mathrm{Gal}$ added only a small increase in cholangiocyte proliferation and fibrogenesis. However, when Gal receptors GalR1 and GalR2 were blocked with specific vivo-morpholino sequences or antagonists, a robust reduction of biliary hyperplasia was observed in Mdr2KO mice. GalR1 suppression with vivo-morpholino sequences strongly inhibited cholangiocyte proliferation, while only slightly reducing fibrogenesis markers. A GalR2-specific antagonist caused a significant reduction in the expression of hepatic fibrosis markers while having no effect on cholangiocyte proliferation in Mdr2KO mice. A Gal receptor pan-antagonist was 
A
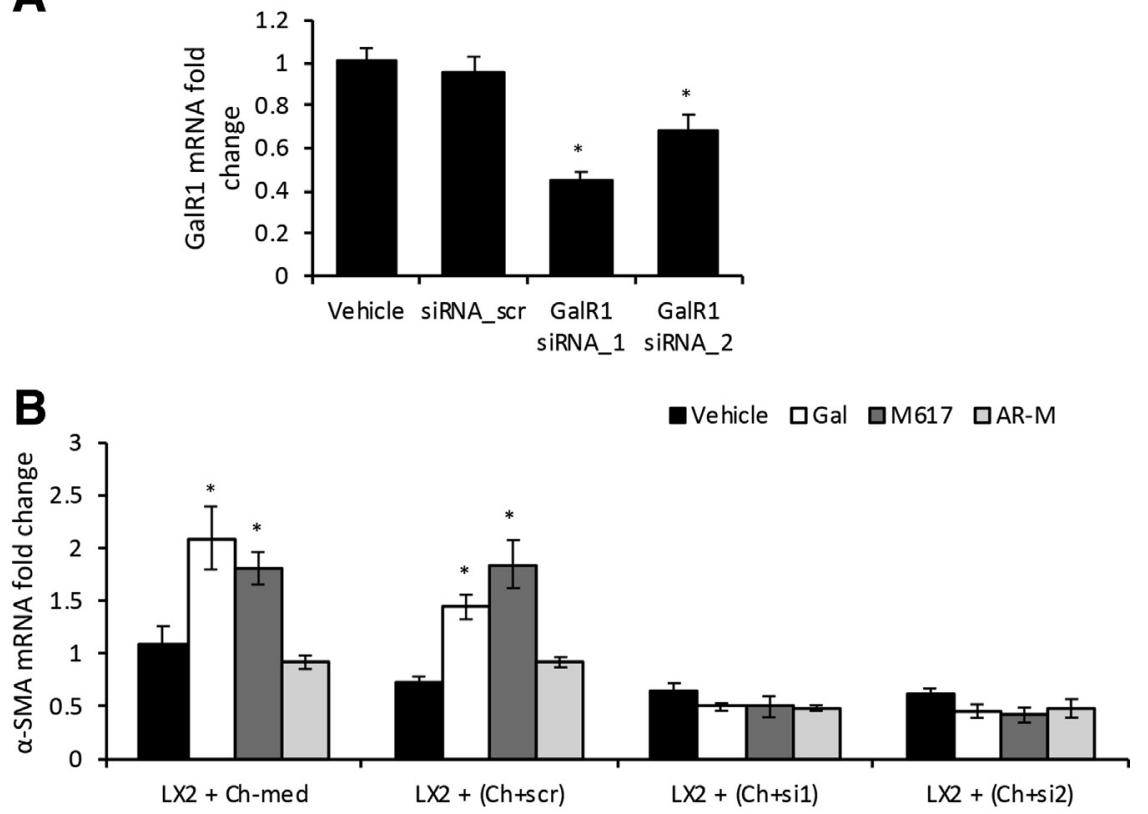

\section{C}

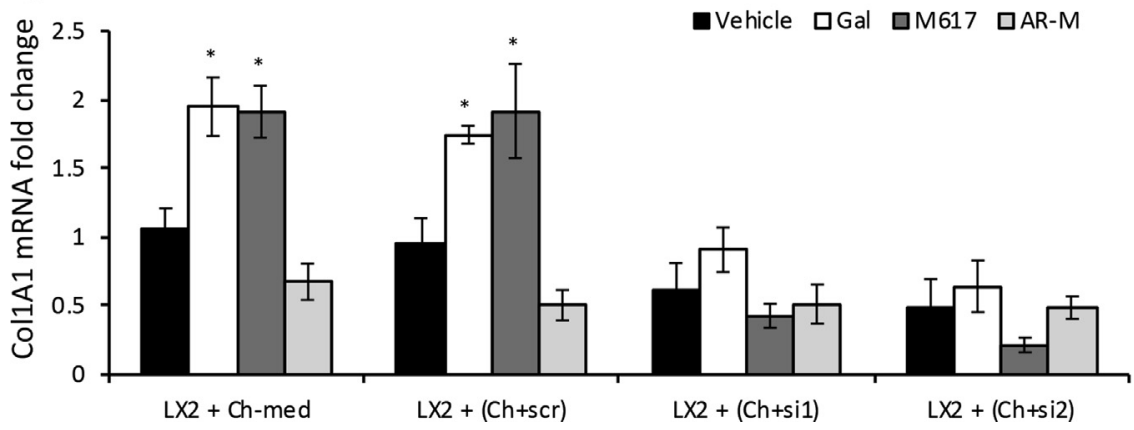

Figure 8 GalR1 is essential for cholangiocytes to mediate LX-2 cell activation by autocrine and paracrine processes. Two different sequences of siRNAs specific for GalR1 (siRNA_1 and siRNA_2) were used to transfect mouse cholangiocytes, versus negative control (scramble siRNA, siRNA_scr). A: GalR1 mRNA relative expression in cholangiocytes transfected with sequence (seq)-1 and seq-2 versus nontransfected cholangiocytes or cholangiocytes transfected with siRNA_scr. B and C: Changes in mRNA expression of $\alpha$-smooth muscle actin ( $\alpha$-SMA; B) and Col1A1 (C) in LX-2 cells when incubated with conditioned media from nontransfected cholangiocytes (Ch-med), cholangiocytes transfected with siRNA_scr $(\mathrm{Ch}+\mathrm{scr})$, cholangiocytes transfected with SiRNA_1 (Ch+si1), or siRNA_2 $(\mathrm{Ch}+\mathrm{si2})$, plus vehicle, Gal, M617, or AR-M. $n=4(\mathbf{A}-\mathbf{C})$. ${ }^{*} P<0.05 \mathrm{Gal} / \mathrm{M} 617 / \mathrm{AR}-\mathrm{M}$ versus vehicle. able to inhibit both biliary hyperplasia and fibrosis in Mdr2KO mice. These results suggest that Gal has multiple functions in the liver, acting through GalR1 and GalR2 receptors that mediate different signaling pathways in cholangiocytes and HSCs.

The distribution of Gal in various types of cells in the liver of FVBN and Mdr2KO mice was also investigated in this study. Gal mRNA was detected in cholangiocytes but not in HSCs or hepatocytes, suggesting that cholangiocytes are able to synthetize Gal locally, in addition to the sympathetic nerves in the liver. These results are consistent with published data showing that the liver releases significant amounts of the peptide during sympathetic activation. ${ }^{22}$ Several studies demonstrated that cholangiocytes acquire neuroendocrine features in hepatic cholestasis and other liver diseases. ${ }^{26}$ During pathologies related to liver injuries, cholangiocytes start proliferating in an atypical manner and express neuroendocrine factors, such as serotonin, ${ }^{27}$ endogenous opioid peptides, ${ }^{28}$ and somatostatin. ${ }^{29}$ Our present results indicate that $\mathrm{Gal}$ is produced in cholangiocytes of Mdr2KO mice, and are in line with previous data from bile duct-ligated rats. ${ }^{21}$
The cellular distribution of Gal receptors GalR1 and GalR2 in the liver, in Mdr2KO and FVBN mice, was also studied by laser-capture microdissection, which indicated that cholangiocytes expressed almost exclusively GalR1, confirming previously published results from bile duct-ligated rats. ${ }^{21}$ In contrast, the HSCs and hepatocytes expressed mainly GalR2. Interestingly, GalR1 mRNA was greater in cholangiocytes from Mdr2KO mice compared with cholangiocytes from FVBN control mice, which is consistent with a larger IBDM in Mdr2KO mice versus FVBN mice.

A possible coordination of GalR1 and GalR2 activation in cholangiocytes and HSCs, in the process of Gal-stimulated fibrogenesis, was investigated by in vitro experiments; and it was concluded that Gal stimulates proliferation of cholangiocytes via GalR1 and enhances HSC activation via GalR2. In cholangiocytes, Gal induced cell proliferation by a signal transduction pathway involving extracellular signalregulated kinase 1/2, ribosomal S6 kinase 1, and cAMP responsive element binding protein activation. ${ }^{21}$ The molecular mechanisms of Gal-induced activation of HSCs are still to be explored. Our findings related to GalR2 being the main Gal receptor expressed in HSCs in vivo are in 
A

- Vehicle $\square$ Galanin $\square$ GalR1 agonist $\square$ GalR2 agonist

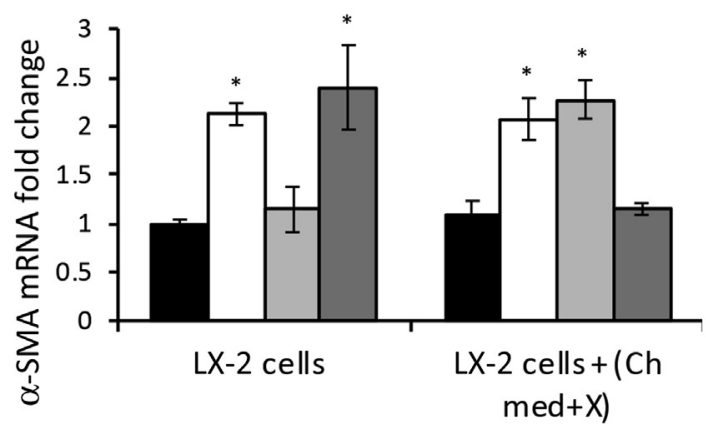

C

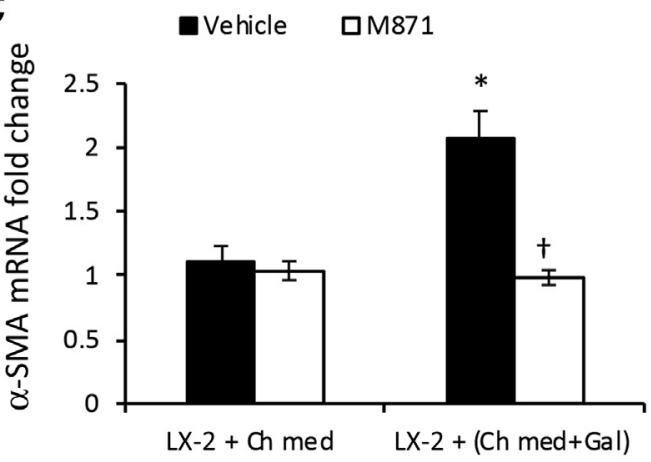

$\mathbf{E}$

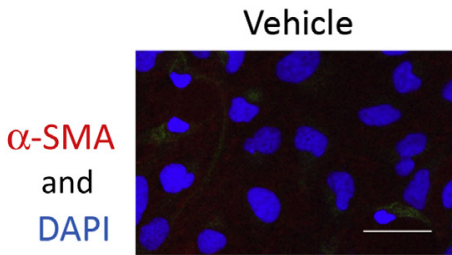

$\mathbf{F}$

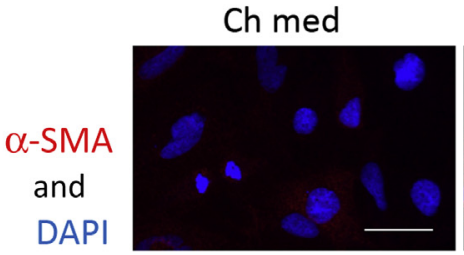

B Vehicle $\square$ Galanin $\square$ GalR1 agonist $\square$ GalR2 agonist

$\stackrel{0}{\circ}$

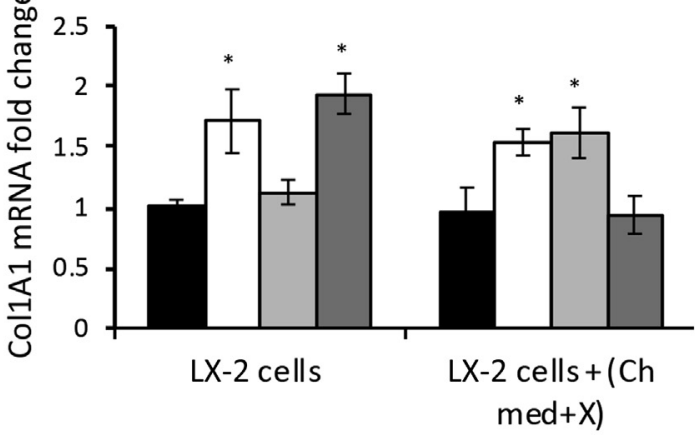

D

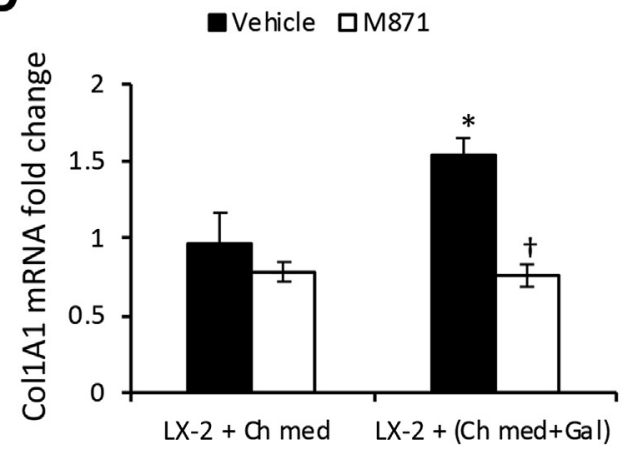

M871

$\mathrm{Gal}+\mathrm{M} 871$
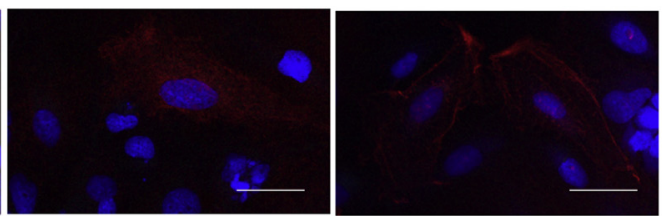

$(\mathrm{Ch}+\mathrm{Gal}) \mathrm{med}$

$(\mathrm{Ch}+\mathrm{M} 871)$ med

$(\mathrm{Ch}+\mathrm{Gal}+\mathrm{M} 871)$ med
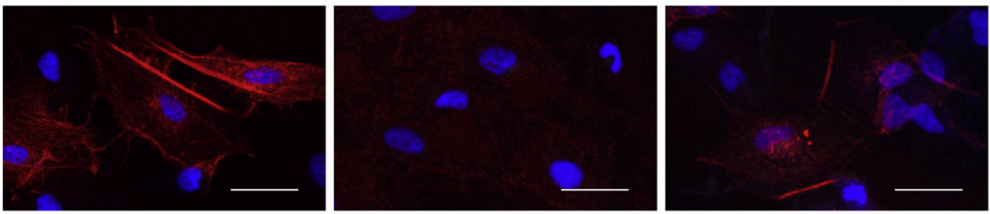

Figure 9 GalR2 is essential for LX-2 cells to become activated by Gal directly or via cholangiocyte-conditioned media. LX-2 cells were treated with vehicle, Gal, GalR1 agonist M617, or GalR2 agonist AR-M, or with conditioned media from cholangiocytes incubated with vehicle, Gal, M617, or AR-M. A and B: Then, $\alpha$-smooth muscle actin ( $\alpha$-SMA; A) and Col1A1 (B) mRNA expression was measured. X represents vehicle, Gal, Gal R1 agonist, or GalR2 agonist. C and D: In parallel, $\alpha$-SMA (C) and Col1A1 (D) mRNAs were quantified in LX-2 cells that were treated with cholangiocyte-conditioned media when cholangiocytes were incubated with vehicle or GalR2 antagonist M871. E: Immunofluorescence (IF) assay of $\alpha$-SMA in LX-2 cells when treated with vehicle, Gal, GalR2 antagonist M871, or Gal + M871. F: IF assay of $\alpha$-SMA in LX-2 cells when treated with conditioned media from cholangiocytes incubated with vehicle, Gal, M871, or Gal + M871. $n=4\left(\right.$ A - D). ${ }^{*} P<0.05$ cholangiocytes incubated with Gal versus cholangiocytes treated with vehicle; ${ }^{\dagger} P<0.05 \mathrm{Gal}, \mathrm{M} 617, \mathrm{Ar}-\mathrm{M}$, and M871 versus vehicle. Scale bars $=50 \mu \mathrm{m}(\mathbf{E}$ and $\mathbf{F})$. Ch-med, cholangiocytes in basal medium; Ch-med and $X$, cholangiocytes in medium plus $X$.

agreement with a study made by $\mathrm{He}$ et al, ${ }^{30}$ using HSC T6 cell line in vitro. However, unlike the results obtained with T6 cell line where GalR2 activation was antifibrotic, the data from both in vivo and in vitro experiments indicate that GalR2 in HSCs contributes to Gal-induced fibrogenesis.

The data from in vivo and in vitro experiments suggest that cholangiocytes produce and secrete more Gal among other factors, with autocrine and paracrine effects, depending on the nature of Gal receptors of the surrounding cells. Thus, cholangiocytes treated with GalR1-specific agonists are able to condition their culture medium so that it induces activation of HSCs via GalR2. We demonstrate that functional GalR1 in cholangiocytes is essential for an indirect activation of HSCs via cholangiocyte-conditioned culture medium. GalR2 in the HSCs is also critical, and GalR2 has to be functional for HSCs to be activated via 


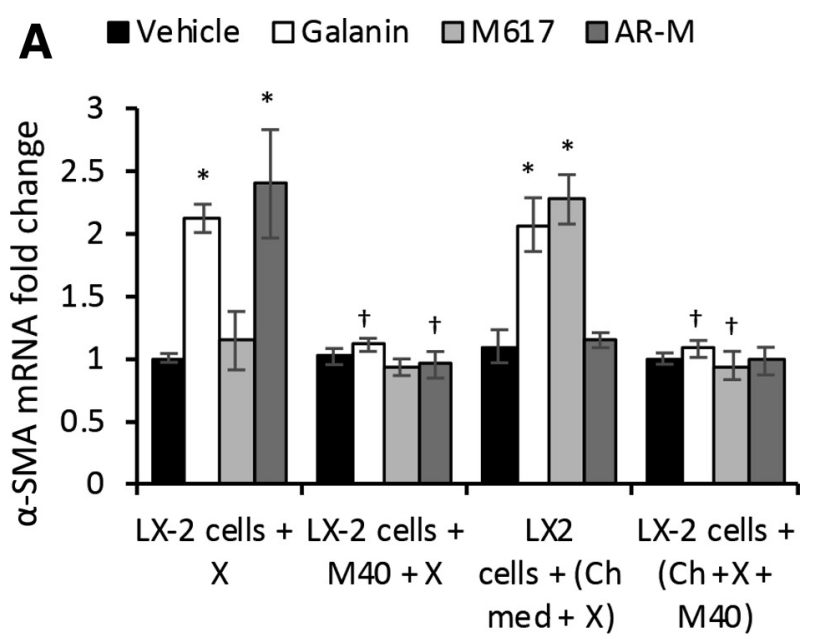

B

Vehicle $\square$ Galanin $\square$ M617 $\square$ AR-M

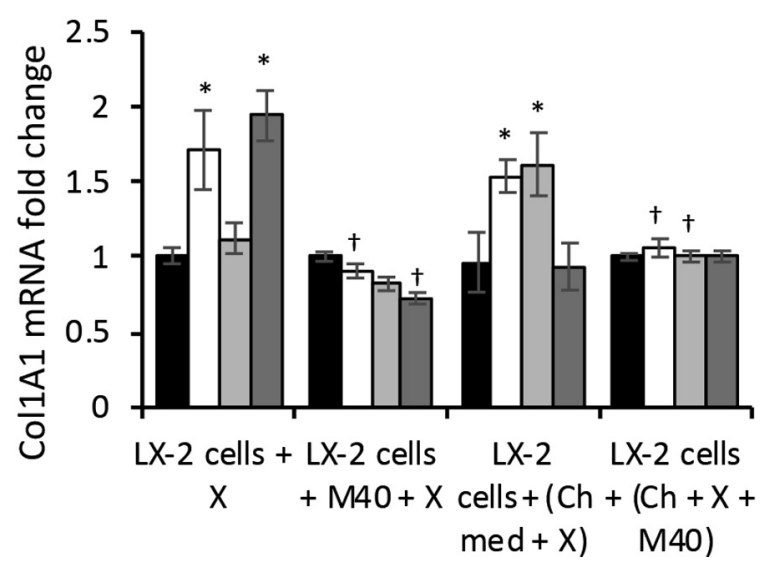

Figure 10 Pan-antagonist M40 inhibits $L X-2$ cell activation when delivered directly or via cholangiocytes (Ch). $\alpha$-Smooth muscle actin ( $\alpha$ SMA; A) and Col1A1 (B) mRNA expression in LX-2 cells when treated with agonist $X$ in the absence or presence of pan-antagonist M40 (LX-2 cells $+X$ \pm M40), or with media from cholangiocytes preincubated with agonist $X \pm$ M40 [LX-2 cells $+(\mathrm{Ch}+\mathrm{X}+$ M40)], where $\mathrm{X}=\mathrm{Gal}$, M617, or AR-M. $n=4$ (A and B). ${ }^{*} P<0.05$ Gal, M617, Ar-M, and M871 versus vehicle; ${ }^{\dagger} P<0.05$ M40 versus absence of M40. Ch-med, Cholangiocytes in basal medium.

cholangiocyte-conditioned medium. In hepatic cholestasis, this study shows that Gal is abnormally increased in the liver of Mdr2KO mice compared with FVBN controls. One mechanism by which Gal is increased in cholestatic mice may be explained by an enhanced pituitary secretion of Gal in response to strong reduction of corticosterone caused by hepatic fibrosis. In Mdr2KO mice, the hypothalamuspituitary-adrenal axis was suppressed, resulting in lower than normal levels of corticosterone. ${ }^{31}$ According to other reports, in adrenalectomized rats, Gal-immunoreactive nerve fibers in the anterior pituitary gland were increased and presented more frequent ramifications. ${ }^{32}$ It was also demonstrated that Gal, as a neuropeptide involved in the regulation of growth axis, is negatively modulated by glucocorticoids (GCs). ${ }^{33,34}$ Thus, dexamethasone significantly decreased somatic growth of male adult rats, while it decreased Gal mRNA level in the hypothalamus and pituitary gland, suggesting a cross talk and opposite actions of Gal and GC in regulating pituitary growth hormone production. ${ }^{33}$ In contrast, Gal was shown to stimulate GC production. Several studies on the molecular mechanisms underlying the neuroendocrine regulation of the hypothalamus-pituitary-adrenal axis demonstrated that Gal stimulated GC secretion in vivo through a receptordependent activation of the adenylate cyclase/protein kinase $\mathrm{A}-$ mediated pathway. ${ }^{35}$ Studies on rat inner adrenocortical cells, which were shown to express GalR1 and GalR2 but not GalR3 receptor, indicated that Gal stimulated corticosterone secretion via these two receptor subtypes that were coupled to the adenylate cyclase/protein kinase A-dependent pathway. ${ }^{36,37}$ However, despite increased Gal in the case of cholestatic disease, there is an impairment of GC production in the adrenals due to multiple and complex factors involved in the disease, including the dysregulation of hypothalamus-pituitary-adrenal axis by bile acids. ${ }^{38-40} \mathrm{In}$ a normal, healthy liver, a fine-tuned balance between neural/ pituitary Gal secretion and GC production in the adrenals maintains the optimal neuroendocrine homeostasis. In the cholestatic liver, though, although $\mathrm{Gal}$ is produced in excess to compensate for the lack of GC, adverse effects of excessive Gal affect the liver in a negative way. Excessive and chronic Gal secretion results in increased hepatic Gal, causing cholangiocyte proliferation, activation of HSCs, and increased hepatic fibrogenesis.

Our data show that Gal receptor inhibitors M871 and M40 cause a decrease in the systemic level of Gal and especially in the liver in Mdr2KO mice, suggesting that these antagonists could be used for reducing the negative effects of excessive Gal in cholestatic liver injury. However, Gal is a neuropeptide with roles in neuroendocrine regulation of a diverse array of central and peripheral organs. The administration of GalR antagonists may affect the normal functioning of other organs than the liver, which exhibit Gal receptors. When creatinine, blood urea nitrogen, and creatine kinase were tested in FVBN and Mdr2KO mice treated with M871 and M40, there were no adverse effects on the kidneys or heart (Supplemental Table S3). Interestingly, according to studies on the effects of M40 antagonist on the heart function, it was found that M40 improved cardiac function of contraction and attenuated cardiac fibrosis in a rodent model of heart failure. ${ }^{41}$

As reported previously, in the Mdr2KO mouse model of cholestatic liver injury, there are sex-related differences in regard to the extent of biliary hyperplasia and hepatic fibrosis, with females tending to have more pronounced injuries than males. ${ }^{31}$ Treatments with anti-inflammatory GC were more effective in male compared with female Mdr2KO mice. ${ }^{31}$ In the present study on the effects of Gal and GalR antagonists on cholestasis in the Mdr2KO model, only few and small sex-related differences were found. Thus, Gal increased desmin expression in females more than in male FVBN and Mdr2KO mice. GalR1 vivo-morpholino 
reduced CK19 with stronger effect in male than in female Mdr2KO mice. GalR2 antagonist M871 decreased $\alpha$-SMA expression more so in males than females. The panantagonist M40 reduced CK19 more effectively in males than females; however, it had equal inhibitory effect on fibrosis in males and females. The overall conclusion is that Gal receptor inhibitors alleviated hepatic fibrosis more effectively in males than in females. This is consistent with published reports indicating that the Gal gene is strongly upregulated by estrogen and fluctuates during the estrous in the rat, according to the circulating level of Gal. ${ }^{42,43}$ Interestingly, our results show Gal peptide being more concentrated in the liver of female than male Mdr2KO mice, which also may explain why M871 and M40 antagonists were less effective at reducing ductular reaction and fibrosis in females than in males.

Galanin-like peptide, although not a product of the Gal gene, has been described as a putative endogenous ligand of GalR2. ${ }^{9,44}$ The preliminary data on possible roles of galanin-like peptide in cholestasis indicated there were no significant changes in serum concentration of galanin-like peptide in bile duct-ligated rat or mouse models, whereas Gal was significantly increased. Therefore, our studies, including the present one in the Mdr2KO mouse model of cholestasis, have focused on Gal. ${ }^{21}$

In this project, we studied the effects of Gal receptor agonists and antagonists on the extent of biliary hyperplasia and fibrosis in Mdr2KO mice. However, it is well known that Gal modulates a multitude of physiological functions, from metabolic and osmotic homeostasis to feeding behavior, nociception, and cognition. ${ }^{45-47}$ GalR1 has been linked to modulatory actions on neurotransmission and nociception, anxiety, and reward behavior, whereas GalR2, with wider expression in central nervous system, is involved in neurotransmission of affective behavior, as well as neurogenesis and neuronal survival in general. ${ }^{9,46}$ Future approaches to use Gal receptor antagonists for treating hepatic cholestasis will have to consider means of confining the delivery of these peptides within the liver rather than systemically. Although the effects of Gal and galanin-like peptide on various neurologic functions have been established, possible negative effects of GalR1 and GalR2 antagonists within the nervous system are still to be investigated.

In conclusion, this study demonstrates that inhibitors of GalR1 and GalR2 receptors reduced cholangiocyte proliferation and hepatic fibrosis markers in Mdr2KO mice. Future experiments are warranted in which both issues of $\mathrm{Gal}$ excess and lack of GC should be addressed, as means for a better management of hepatic cholestasis and cirrhosis.

\section{Author Contributions}

A.D.P., S.G., E.W., G.F., N.P., H.B., M.D., E.H.R., and R.J. performed experiments and analyzed data; S.G. and E.W. performed animal experiments and collected tissue; S.D., A.D.P., and M.M. designed the study. S.D. and A.D.P. wrote the manuscript; A.D.P., S.G., G.F., E.W., N.P., H.B., M.D., R.J., E.H.R., M.M., and S.D. edited and approved the final manuscript.

\section{Supplemental Data}

Supplemental material for this article can be found at http://doi.org/10.1016/j.ajpath.2019.10.023.

\section{References}

1. Ch'ng JL, Christofides ND, Anand P, Gibson SJ, Allen YS, Su HC, Tatemoto K, Morrison JF, Polak JM, Bloom SR: Distribution of galanin immunoreactivity in the central nervous system and the responses of galanin-containing neuronal pathways to injury. Neuroscience $1985,16: 343-354$

2. Melander T, Staines WA, Rokaeus A: Galanin-like immunoreactivity in hippocampal afferents in the rat, with special reference to cholinergic and noradrenergic inputs. Neuroscience 1986, 19:223-240

3. Melander T, Hokfelt T, Nilsson S, Brodin E: Visualization of galanin binding sites in the rat central nervous system. Eur J Pharmacol 1986, 124:381-382

4. Skofitsch G, Jacobowitz DM: Quantitative distribution of galanin-like immunoreactivity in the rat central nervous system. Peptides 1986, 7 : 609-613

5. Koshiyama H, Kato $Y$, Inoue $T$, Murakami $Y$, Ishikawa $Y$, Yanaihara N, Imura H: Central galanin stimulates pituitary prolactin secretion in rats: possible involvement of hypothalamic vasoactive intestinal polypeptide. Neurosci Lett 1987, 75:49-54

6. Murakami Y, Kato Y, Koshiyama H, Inoue T, Yanaihara N, Imura H Galanin stimulates growth hormone (GH) secretion via GH-releasing factor (GRF) in conscious rats. Eur J Pharmacol 1987, 136:415-418

7. Inoue $\mathrm{T}$, Kato $\mathrm{Y}$, Koshiyama H, Yanaihara N, Imura H: Galanin stimulates the release of vasoactive intestinal polypeptide from perifused hypothalamic fragments in vitro and from periventricular structures into the cerebrospinal fluid in vivo in the rat. Neurosci Lett $1988,85: 95-100$

8. Kaplan LM, Spindel ER, Isselbacher KJ, Chin WW: Tissue-specific expression of the rat galanin gene. Proc Natl Acad Sci U S A 1988, 85:1065-1069

9. Lang R, Gundlach AL, Holmes FE, Hobson SA, Wynick D, Hokfelt T, Kofler B: Physiology, signaling, and pharmacology of galanin peptides and receptors: three decades of emerging diversity. Pharmacol Rev 2015, 67:118-175

10. Yun R, Dourmashkin JT, Hill J, Gayles EC, Fried SK, Leibowitz SF: PVN galanin increases fat storage and promotes obesity by causing muscle to utilize carbohydrate more than fat. Peptides 2005, 26: 2265-2273

11. Kyrkouli SE, Stanley BG, Seirafi RD, Leibowitz SF: Stimulation of feeding by galanin: anatomical localization and behavioral specificity of this peptide's effects in the brain. Peptides 1990, 11:995-1001

12. Wynick D, Smith DM, Ghatei M, Akinsanya K, Bhogal R, Purkiss P, Byfield P, Yanaihara N, Bloom SR: Characterization of a highaffinity galanin receptor in the rat anterior pituitary: absence of biological effect and reduced membrane binding of the antagonist M15 differentiate it from the brain/gut receptor. Proc Natl Acad Sci U S A 1993, 90:4231-4235

13. Parker EM, Izzarelli DG, Nowak HP, Mahle CD, Iben LG, Wang J, Goldstein ME: Cloning and characterization of the rat GALR1 galanin receptor from Rin14B insulinoma cells. Brain Res Mol Brain Res 1995, 34:179-189 
14. Howard AD, Tan C, Shiao LL, Palyha OC, McKee KK, Weinberg DH, Feighner SD, Cascieri MA, Smith RG, Van Der Ploeg LH, Sullivan KA: Molecular cloning and characterization of a new receptor for galanin. FEBS Lett 1997, 405:285-290

15. Wang S, He C, Hashemi T, Bayne M: Cloning and expressional characterization of a novel galanin receptor: identification of different pharmacophores within galanin for the three galanin receptor subtypes. J Biol Chem 1997, 272:31949-31952

16. Depczynski B, Nichol K, Fathi Z, Iismaa T, Shine J, Cunningham A: Distribution and characterization of the cell types expressing GALR2 mRNA in brain and pituitary gland. Ann N Y Acad Sci 1998, 863: 120-128

17. Habert-Ortoli E, Amiranoff B, Loquet I, Laburthe M, Mayaux JF: Molecular cloning of a functional human galanin receptor. Proc Natl Acad Sci U S A 1994, 91:9780-9783

18. Fathi Z, Cunningham AM, Iben LG, Battaglino PB, Ward SA, Nichol KA, Pine KA, Wang J, Goldstein ME, Iismaa TP, Zimanyi IA: Cloning, pharmacological characterization and distribution of a novel galanin receptor. Brain Res Mol Brain Res 1997, 51:49-59

19. Smith KE, Walker MW, Artymyshyn R, Bard J, Borowsky B, Tamm JA, Yao WJ, Vaysse PJ, Branchek TA, Gerald C, Jones KA: Cloned human and rat galanin GALR3 receptors: pharmacology and activation of G-protein inwardly rectifying $\mathrm{K}+$ channels. J Biol Chem 1998, 273:23321-23326

20. Waters SM, Krause JE: Distribution of galanin-1, -2 and -3 receptor messenger RNAs in central and peripheral rat tissues. Neuroscience 2000, 95:265-271

21. McMillin M, Frampton G, Grant S, DeMorrow S: The neuropeptide galanin is up-regulated during cholestasis and contributes to cholangiocyte proliferation. Am J Pathol 2017, 187:819-830

22. Kowalyk S, Veith R, Boyle M, Taborsky GJ Jr: Liver releases galanin during sympathetic nerve stimulation. Am J Physiol 1992, 262: E671-E678

23. Mundinger TO, Taborsky GJ Jr: Differential action of hepatic sympathetic neuropeptides: metabolic action of galanin, vascular action of NPY. Am J Physiol Endocrinol Metab 2000, 278:E390-E397

24. Mauad TH, van Nieuwkerk CM, Dingemans KP, Smit JJ, Schinkel AH, Notenboom RG, van den Bergh Weerman MA, Verkruisen RP, Groen AK, Oude Elferink RP, van der Valk MA, Borst P, Offerhaus JA: Mice with homozygous disruption of the mdr2 P-glycoprotein gene: a novel animal model for studies of nonsuppurative inflammatory cholangitis and hepatocarcinogenesis. Am J Pathol 1994, 145:1237-1245

25. Trauner M, Fickert P, Wagner M: MDR3 (ABCB4) defects: a paradigm for the genetics of adult cholestatic syndromes. Semin Liver Dis 2007, 27:77-98

26. Alvaro D, Mancino MG, Glaser S, Gaudio E, Marzioni M, Francis H, Alpini G: Proliferating cholangiocytes: a neuroendocrine compartment in the diseased liver. Gastroenterology 2007, 132: 415-431

27. Marzioni M, Glaser S, Francis H, Marucci L, Benedetti A, Alvaro D, Taffetani S, Ueno Y, Roskams T, Phinizy JL, Venter J, Fava G, Lesage GD, Alpini G: Autocrine/paracrine regulation of the growth of the biliary tree by the neuroendocrine hormone serotonin. Gastroenterology 2005, 128:121-137

28. Marzioni M, Alpini G, Saccomanno S, de Minicis S, Glaser S, Francis H, Trozzi L, Venter J, Orlando F, Fava G, Candelaresi C, Macarri G, Benedetti A: Endogenous opioids modulate the growth of the biliary tree in the course of cholestasis. Gastroenterology 2006, 130:1831-1847

29. Tietz PS, Alpini G, Pham LD, Larusso NF: Somatostatin inhibits secretin-induced ductal hypercholeresis and exocytosis by cholangiocytes. Am J Physiol 1995, 269:G110-G118

30. He L, Li Z, Zhou D, Ding Y, Xu L, Chen Y, Fan J: Galanin receptor 2 mediates antifibrogenic effects of galanin on hepatic stellate cells. Exp Ther Med 2016, 12:3375-3380
31. Petrescu AD, Grant S, Frampton G, Kain J, Hadidi K, Williams E, McMillin M, DeMorrow S: Glucocorticoids cause gender-dependent reversal of hepatic fibrosis in the MDR2-knockout mouse model. Int J Mol Sci 2017, 18:2389

32. Liu YY, Ju G: Galanin-like immunoreactive nerve fibres in the anterior pituitary of the normal and adrenalectomized rat. Acta Histochem 1998, 100:149-156

33. Brogan RS, Coney LK, Wehrenberg WB, Beretta G, Giustina A: Short-term glucocorticoid administration decreases both hypothalamic and pituitary galanin synthesis in the adult male rat. Metabolism 1999, 48:792-796

34. Giustina A, Voltz DM, Teik J, Wehrenberg WB: Galanin counteracts the inhibitory effects of glucocorticoids on growth hormone secretion in the rat. Metabolism 1995, 44:224-227

35. Mazzocchi G, Rebuffat P, Gottardo G, Malendowicz LK, Nussdorfer GG: Galanin stimulates glucocorticoid secretion in rats through a receptor-dependent activation of the adenylate cyclase/protein kinase A-dependent signaling pathway. Peptides 1998, 19:891-895

36. Andreis PG, Malendowicz LK, Rebuffat P, Spinazzi R, Ziolkowska A, Nussdorfer GG: Galanin enhances corticosterone secretion from dispersed rat adrenocortical cells through the activation of GAL-R1 and GAL-R2 receptors coupled to the adenylate cyclase-dependent signaling cascade. Int J Mol Med 2007, 19: $149-155$

37. Belloni AS, Malendowicz LK, Rucinski M, Guidolin D, Nussdorfer GG: Galanin stimulates cortisol secretion from human adrenocortical cells through the activation of galanin receptor subtype 1 coupled to the adenylate cyclase-dependent signaling cascade. Int J Mol Med 2007, 20:859-864

38. Quinn M, McMillin M, Galindo C, Frampton G, Pae HY, DeMorrow S: Bile acids permeabilize the blood brain barrier after bile duct ligation in rats via Rac1-dependent mechanisms. Dig Liver Dis 2014, 46:527-534

39. McMillin M, Frampton G, Quinn M, Divan A, Grant S, Patel N, Newell-Rogers K, DeMorrow S: Suppression of the HPA axis during cholestasis can be attributed to hypothalamic bile acid signaling. Mol Endocrinol 2015, 29:1720-1730

40. McNeilly AD, Macfarlane DP, O'Flaherty E, Livingstone DE, Mitic T, McConnell KM, McKenzie SM, Davies E, Reynolds RM, Thiesson HC, Skott O, Walker BR, Andrew R: Bile acids modulate glucocorticoid metabolism and the hypothalamic-pituitary-adrenal axis in obstructive jaundice. $\mathrm{J}$ Hepatol 2010, 52:705-711

41. Chen A, Li M, Song L, Zhang Y, Luo Z, Zhang W, Chen Y, He B: Effects of the galanin receptor antagonist M40 on cardiac function and remodeling in rats with heart failure. Cardiovasc Ther 2015, 33: 288-293

42. Kaplan LM, Gabriel SM, Koenig JI, Sunday ME, Spindel ER, Martin JB, Chin WW: Galanin is an estrogen-inducible, secretory product of the rat anterior pituitary. Proc Natl Acad Sci U S A 1988, $85: 7408-7412$

43. Merchenthaler I, Lopez FJ, Lennard DE, Negro-Vilar A: Sexual differences in the distribution of neurons coexpressing galanin and luteinizing hormone-releasing hormone in the rat brain. Endocrinology 1991, 129:1977-1986

44. Ohtaki T, Kumano S, Ishibashi Y, Ogi K, Matsui H, Harada M, Kitada C, Kurokawa T, Onda H, Fujino M: Isolation and cDNA cloning of a novel galanin-like peptide (GALP) from porcine hypothalamus. J Biol Chem 1999, 274:37041-37045

45. Gundlach AL: Galanin/GALP and galanin receptors: role in central control of feeding, body weight/obesity and reproduction? Eur J Pharmacol 2002, 440:255-268

46. Liu HX, Hokfelt T: The participation of galanin in pain processing at the spinal level. Trends Pharmacol Sci 2002, 23:468-474

47. Crawley JN: The role of galanin in feeding behavior. Neuropeptides 1999, 33:369-375 